\section{EMBRYRIDDLE \\ Aeronautical University}

SCHOLARLY COMMONS

\section{International Journal of Aviation,} Aeronautics, and Aerospace

\title{
Efficient General Computational Method for Estimation of Standard Atmosphere Parameters
}

Nihad E. Daidzic Ph.D., Sc.D.

AAR Aerospace Consulting, LLC, aaraerospace@cs.com

Follow this and additional works at: https://commons.erau.edu/ijaaa

Part of the Aerodynamics and Fluid Mechanics Commons, Atmospheric Sciences Commons, Engineering Physics Commons, Management and Operations Commons, and the Numerical Analysis and Computation Commons

\section{Scholarly Commons Citation}

Daidzic, N. E. (2015). Efficient General Computational Method for Estimation of Standard Atmosphere Parameters. International Journal of Aviation, Aeronautics, and Aerospace, 2(1). https://doi.org/ 10.15394/ijaaa.2015.1053

This Article is brought to you for free and open access by the Journals at Scholarly Commons. It has been accepted for inclusion in International Journal of Aviation, Aeronautics, and Aerospace by an authorized administrator of Scholarly Commons. For more information, please contact commons@erau.edu. 
The Earth's atmosphere is a dynamic system of enormous complexity. It is very difficult to define the exact size, mass, and weight of the Earth's atmosphere, but in many respects it is a very thin layer, compared to Earth's radius, of selected gases that shrouds our planet. The gravitational pull provides the essential force in aerostatic (and hydrostatic) balance. Our atmosphere is daily gaining some (meteorites) and losing some of its mass (lighter gases escaping gravity due to its thermal motion) and apparently it is in dynamic equilibrium. The lower layers of the atmosphere can be assumed to be consisting mostly of non-interacting and chemically inert gases. No single book on atmospheric science and much less a single article could possibly hope to account for all the rich details and complex physical and chemical processes simultaneously taking place throughout Earth's atmosphere.

The atmosphere of the planet Earth consists of a finite, but enormous number of molecules, atoms, and ions in thermal motion. To follow temporal and spatial histories of every elementary particle in our atmosphere would be akin to a definition of insanity and it is not really theoretically possible due to quantum uncertainty, the impossibility to determine the initial conditions, and the rapidly accumulating errors associated with the numerical integration. Luckily, the methods of the classical and the quantum statistical physics (or thermodynamics) and the kinetic theory of gases (Holman, 1980; Lay, 1963; Saad, 1966) come to assistance in defining average behavior of all elementary particles in each small but finite-volume parcel of air (Dutton, 2002). Hence, it becomes possible to define crucial thermodynamic intensive parameters such as pressure, density and temperature which for individual atoms and molecules makes no sense.

Knowledge of those critical air parameters is essential information for pressure altimeter calibration; aircraft design; aircraft performance, testing, and certification, etc. For example, knowing the operating pressure differentials between cabin altitude (airplane's pressurized vessel) and outside atmosphere is crucial in airplane structural design and essential in high-altitude flight safety (Daidzic \& Simones, 2010). Terrestrial weather and atmospheric characteristics are constantly changing - spatially and temporally. To make the problem tractable, useful, and arrive at a mutually-agreed still and (neutrally) stable atmosphere, that in reality never exists, the concept of ISA (International Standard Atmosphere) was introduced.

The atomic and molecular structure of air, which in itself is a mixture of many atomic and molecular gases is thus replaced with the notion of continuum (low-Knudsen number fluid mechanics) and a finite-size fluid parcel. Subsequently, thermodynamic properties defined for fluid parcels of small but 
finite size change continuously from point to point (Dutton, 2002). A continuum principle implies that individuality of single or even larger groups of atoms and molecules is entirely lost in a huge crowd of elementary particles (e.g., $10^{21}$ particles in one inch $^{3}$ ). This approximation enables implementation of the powerful and well developed mathematical method of integro-differential analysis. Only at very high altitudes and very low atmospheric pressures is the meaning of the continuum lost and kinetic theories of gases and statistical mechanic (classical and quantum) must be used to describe behaviors of rarefied gases (large-Knudsen number fluid mechanics). In the case of rarefied (dilute) gases, collision frequencies of elementary particles becomes too low and the mean-free-path too long $(K n \geq 1)$ for the gas to be considered a continuum. However, even such dilute atmosphere will provide sufficient drag to deorbit very low-altitude (100-200 km) satellites in a matter of several days to a few weeks.

The U.S.-based NOAA (National Oceanic and Atmospheric Administration) along with other international standards of Earth atmosphere essentially cover the range of altitudes from zero MSL (Mean Sea Level) to about 1000 km (ICAO, 1993; ISO, 1975; NOAA, 1976). The ICAO (International Civil Aviation Organization), ISO (International Organization for Standardization), and the U.S. standards give quite detailed descriptions of the fundamental processes related to the atmosphere. For example, ICAO's standard provides atmospheric parameters in tabular form for levels up to $80 \mathrm{~km}$ and the underlying equations used in calculations of atmospheric parameters. The main purpose of ICAO's standard is intended for use in calculations in design of aircraft, in presenting test results of aircraft and their components, and in facilitating standardization in the development and calibration of instruments. There is no space here to dwell on the minute differences and particularities for various atmospheric standards. However, these standards are not necessarily user-friendly and some important explanations and clarifications are missing. All these various standards (ICAO, ISO, NOAA), which are for the most part are identical, will be simply referred to as ISA (ISO standard).

Tabular values presented as look-up tables are not very practical when ISA quantities need to be directly implemented in other calculations. There is still a need to translate mathematical equations into programming language (e.g., Fortran, Matlab, Basic, Pascal, C++, etc.). All the calculations for arbitrary altitude must be performed starting from MSL and then marching sequentially through each layer. This is tedious and cumbersome. One essential fact missing in atmospheric standards is the actual definition of MSL or the orthometric height. 
It is a common practice in many books on aeronautical and aerospace engineering (Anderson, 2012; Asselin, 1997; Bertin \& Cummings, 2009; Eshelby, 2000; Filippone, 2006, 2012; Hale, 1984; Mair \& Birdsall, 1992; McCormick, 1995; Nicolai \& Carichner, 2010; Phillips, 2004; Saarlas, 2007; Torenbeek, 2013; Vinh, 1993) as well as in some more advanced aviation-science-oriented aerodynamics books (Hubin, 1992; Hurt 1965) to present abbreviated ISA tables (mostly for troposphere and tropopause). Occasionally some working equations that mathematically describe the functional relationship between the critical thermodynamic air parameters (pressure, density and temperature) are given. A common mistake noted in many references is confusing the geopotential for the orthometric altitudes and vice versa. Some ISA calculators are available on the Internet, but this is mostly a black-box approach offering no insight and almost impossible to incorporate in user-designed software. However, in the opinion of this author not enough background is given to students and practitioners of aeronautical engineering and aviation sciences to understand the standard atmospheric models. Hence, a general computational method and working equations have been derived here that allow for rapid calculations of any atmospheric layer. Standard atmosphere implicitly assumes the spherical Earth. However, the "true" shape of the Earth is Geoid defining a particular equipotential surface and approximating MSL. On the other hand, GPS-heights (U.S. based Global Positioning System) uses reference WGS-84 (World Geodetic System) which is essentially equivalent to the IERS (International Earth Rotation and Reference System) ellipsoid which is the simple mathematical approximation of the Geoid. More on the shape of the Earth and its crucially important gravitational field will be covered in a subsequent article. Geometric heights are MSL or orthometric heights or heights above the Geoid.

The basic motivation behind this research article is to provide more indepth understanding of standard atmospheric models, derive and provide more adequate non-dimensional working equations, and in parallel more advanced computational methods for calculations of the lower ISA (up to $86 \mathrm{~km}$ orthometric altitude). The effects of the decreasing gravitational acceleration on the vertical pressure and density distribution will be highlighted. The standard atmospheric model will be described in more detail than is normally done and the more general approach to solutions of working equations will be given for most important atmospheric parameters. A table of non-dimensional parameters will be also given as functions of orthometric and geopotential heights. Atmospheric masses, weights, and scale heights will be calculated for each ISA layer using numerical integration methods. 


\section{The Earth's Atmosphere}

The Earth's atmosphere, shown in Figure 1, is a relatively thin multicomponent gaseous layer. For example, it shields us from the harmful solar ultraviolet radiation $(<380$ nanometers or $\mathrm{nm}$ ) and provides life-sustaining oxygen-rich environment. The complexity of various physical-chemical processes that continuously occur in the atmosphere is overwhelming. Thus, idealizations and simplified mathematical models of the atmosphere need to be introduced to make this apparent chaos of simultaneous processes comprehensible and tractable.

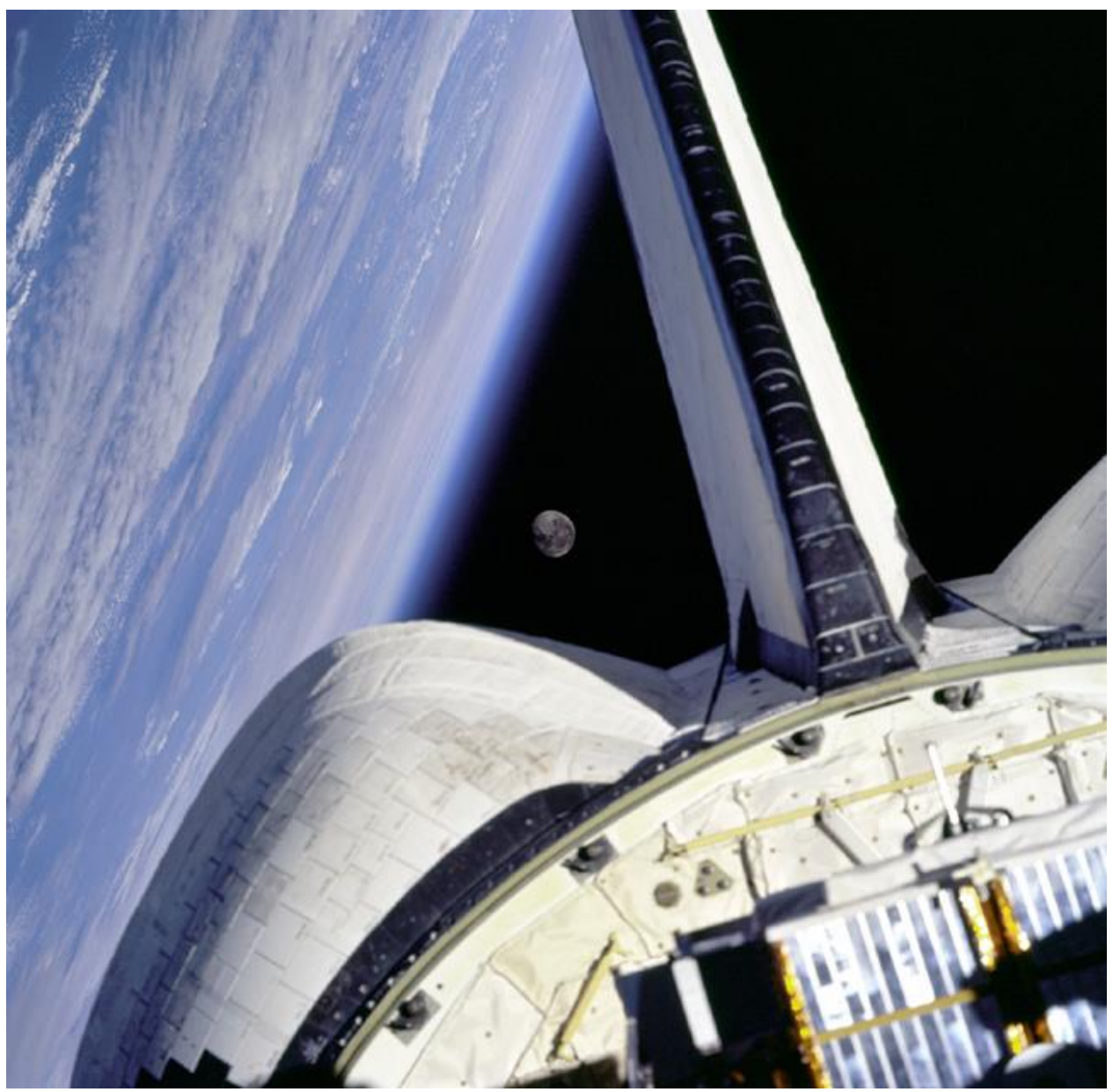

Figure 1. Earth's thin and fragile atmosphere as seen from the Space Shuttle orbiter (with our Moon in background). Image courtesy of National Aeronautics and Space Administration/Marshall Space Flight Center (NASA-MSFC). 
In order to standardize, evaluate, and test aerospace designs it is imperative to have one mutually agreed standard (convention) of still and dry atmosphere, that is, ISA (ISO, 1975). Other atmospheric "standards" are in use as well. Most notably the ICAO standard atmosphere (ICAO, 1993) and the U.S. Standard Atmospheric model (NOAA, 1976). For the most part, these standard models are identical. Models of non-standard atmospheric models such as hot day, cold day, tropic day, and arctic day (MIL-STD-210A) are also available (Filippone 2006, 2012; Nicolai \& Carichner, 2010), but will not be discussed. Essentially, once the concept of ISA is understood it is not difficult to design offstandard and various other atmospheric models. The very rarefied high-altitude atmosphere used in drag calculation of LEO (Low Earth Orbit) satellite orbits is beyond the scope of this article.

The history of ISA is convoluted. Many attempts were made in the $20^{\text {th }}$ century with the progress in aeronautics to standardize aircraft performance calculations as well as calibration of pressure altimeters. In 1952 ICAO finally agreed to adopt an international standard. Subsequently, ISO published ISA as international standard ISO 2533:1975 (ISO, 1975) and then published addendums in 1985 and 1997. In addition to ISA, there is also ICAO standard atmosphere (ICAO, 1993) and the U.S. Standard Atmosphere (NOAA, 1976) with slight differences compared to ISA and mostly in the upper layers of the atmosphere. A short history of ISA is given by Anderson (2012).

The two major low-altitude atmospheric layers are troposphere, with the negative TLR (Temperature Lapse Rate) of about $2^{\circ} \mathrm{C} / 1000 \mathrm{ft}\left(-6.5^{\circ} \mathrm{C}\right.$ per $\left.\mathrm{km}\right)$ that extends from SL (Sea Level) to 11 geopotential km, and the stratosphere that extends from 11 to $47 \mathrm{~km}$. The lower level of stratosphere or tropopause (isothermal layer) extends from 11 to 20 geopotential km's $(36,089$ to $65,616 \mathrm{ft})$ with zero temperature lapse rate (constant temperature). The upper part of the stratosphere is characterized by two different positive temperature gradient regions. The first gradient layer has a positive temperature lapse rate of about $1^{0} \mathrm{C} / \mathrm{km}$ and extends from 20 to $32 \mathrm{~km}$. The second gradient layer in the stratosphere has a positive TLR of $2.8^{\circ} \mathrm{C} / \mathrm{km}$ and extends from 32 to $47 \mathrm{~km}$ where yet another isothermal layer starts (stratopause - part of mesosphere). Stratopause (47 to $51 \mathrm{~km}$ ) which has uniform temperature, or zero TLR, is a part of mesosphere which extends to geopotential $84.852 \mathrm{~km}$ (86 km orthometric). After stratopause, the upper mesosphere also consists of two negative constant TLR regions extending from 51 to $71 \mathrm{~km}$ and from 71 to 84.852 geopotential $\mathrm{km}$. The Earth's atmosphere thus approximately consists of several isothermal and gradient layers (regions). Troposphere, stratosphere, and mesosphere are integral parts of the homosphere. 
For all practical purposes the basic constituents of dry air do not change until about 80 to $86 \mathrm{~km}$ (about 282,000 ft) orthometric height. Thus this region is typically called homosphere (Iribarne \& Cho, 1980). Above 86 orthometric km up to about $1,000 \mathrm{~km}$ the atmosphere is dramatically changing and is called a heterosphere. Thermosphere and Exosphere are thus parts of heterosphere. Exosphere consists of elementary particles moving in ballistic trajectories some of which escape Earth's gravity. Occasionally such particles will travel for hundreds of kilometers before colliding with another particle.

The lower atmosphere is very well mixed resulting in essentially constant ratios of its main constituents. Molecular nitrogen $\left(\mathrm{N}_{2}\right)$ is the most abundant atmospheric gas with diatomic molecular oxygen $\left(\mathrm{O}_{2}\right)$ coming as second. Many noble gases such as Argon (Ar), Neon (Ne), Helium (He), Krypton (Kr), and Xenon $(\mathrm{Xe})$ are found in its inherently stable atomic states. The resulting total thermodynamic pressures and volumes are sums of respective partial pressures and volumes of its constituents.

Alarmingly, the concentration of the carbon dioxide $\left(\mathrm{CO}_{2}\right)$ is increasing in the atmosphere and currently becoming an extraordinary problem due to its greenhouse-gas nature. According to Trenberth and Smith (2005) the amount of atmospheric $\mathrm{CO}_{2}$ increased from $270 \mathrm{ppm}$ (parts-per-million) to over $370 \mathrm{ppm}$ in the period of the last 200 years or from the pre-industrial estimates till today. Water $\left(\mathrm{H}_{2} \mathrm{O}\right)$ is found in varying amounts in all three states of the matter in the lower atmosphere. Thus the atmospheric standard cannot reasonably account for humid air and water vapor variability. Additionally, molecular hydrogen $\mathrm{H}_{2}$, Methane $\left(\mathrm{CH}_{4}\right)$ and many other gases are found in trace amounts.

Based on numerous measurements (gas balloons, sounding rockets, research airplanes, LEO satellites, etc.) over many decades and over various geographical locations on Earth, current standard atmospheric model consists of several discrete temperature layers of which the first few (homosphere) are summarized in Table 1 (ICAO, 1993; ISO, 1975; NOAA, 1976). A good basic introduction into Earth's atmosphere is given by Iribarne and Cho (1980). According to Iribarne and Cho, $90 \%$ of the atmospheric mass is contained within approximately the first $20 \mathrm{~km}$ (top $100 \mathrm{mbar}$ level). Iribarne and Cho also stated that $99.9 \%$ of the atmospheric mass is contained within the first $50 \mathrm{~km}$ (top 1 mbar level).

Although the concept of MSL is habitually used in aeronautics and aviation it is basically never defined. As expected, the issue is much more complex than it may appear at the first sight. First, Earth is not a perfect sphere. 
Second, it rotates. Earth's rotation controls its shape and indirectly spatial distribution of the gravitational mass and attraction. To make things even more complicated, Earth's mass-density is not uniformly distributed due to geological activity implying existence of many gravity anomalies. Earth not only rotates, but also nutates, precesses, and wobbles in a very complicated fashion. The gravitational pull will decrease with the square of the distance in accordance with the classical Newton's law of universal gravitation. Air parcels at higher altitude will thus experience lesser gravitational attractions. Again, more on Earth's gravitation and shape will be covered in a subsequent article.

Table 1

Atmospheric ISA Layers (Homosphere)

\begin{tabular}{lcc}
\hline Atmospheric Level & $\begin{array}{c}\text { Altitude Range } \\
\text { (Geopotential) }[\mathrm{km}]\end{array}$ & $\begin{array}{c}\text { Temperature Lapse Rate } \\
d T / d H[\mathrm{~K} / \mathrm{m}]\end{array}$ \\
\hline Troposphere & $0-11$ & -0.0065 \\
Tropopause (SS I) & $11-20$ & 0 \\
Stratosphere II & $20-32$ & +0.001 \\
Stratosphere III & $32-47$ & +0.0028 \\
Stratopause (MS I) & $47-51$ & 0 \\
Mesosphere II & $51-71$ & -0.0028 \\
Mesosphere III & $71-84.852$ & -0.0020 \\
\hline
\end{tabular}

In actual analysis of standard atmosphere, Earth's non-sphericity and nonuniform mass-density is thus neglected. Gravitational equipotential surfaces are then concentric spheres with gravitational acceleration vectors being equivalent to the radius vectors emanating from the geocenter (geometric center) and barycenter (mass center). An average surface gravitational acceleration is based on the adopted standard mid-latitude value for the true Earth. In that case gravitational acceleration changes only as a function of altitude above the Geoid that can be written with sufficient accuracy below $500 \mathrm{~km}(1,640,000 \mathrm{ft})$ as:

$$
\begin{aligned}
& g=g_{o}\left(\frac{R_{0}}{R_{0}+z}\right)^{2} \approx g_{o}\left(1-2 \frac{z}{R_{0}}\right) \\
& g_{o}=9.80665 \mathrm{~m} / \mathrm{s}^{2}=32.174 \mathrm{ft} / \mathrm{s}^{2} \quad R_{0}=6,371.0 \mathrm{~km}
\end{aligned}
$$

The U.S. Standard Atmosphere (NOAA, 1976) uses average radius of $6,356.766 \mathrm{~km}$ as it apparently corresponds to Earth radius at mid-latitude where 
standard gravitational acceleration exists. However, the NOAA (1976) radius is actually almost exactly the polar (and minimum Earth's) radius, which for the spherical-Earth approximation, does not seem to be fully appropriate. Therefore, an average spherical-Earth radius was used here resulting in small difference from NOAA's (1976) values at very high altitudes (three meters at $86 \mathrm{~km}$ ). The change in standard averaged gravitational acceleration using Equation 1 is less than $0.8 \%$ for heights below $25 \mathrm{~km}$ compared to SL values. Linear approximation in Equation 1 at $25 \mathrm{~km}$ results in truncation error of less than $0.05 \%$. Only at very high altitudes (suborbital and orbital flight) is the reduction of gravity with height really crucial, but by that time very little is left of Earth's atmosphere.

\section{The Thermodynamic Model of Air}

Atmospheric air at lower altitudes is assumed to be a still dry mixture of chemically-stable non-interacting gases that follow thermally and calorically perfect- or ideal-gas constitutive equation of state (Liepmann \& Roshko, 2001). The general virial equation of state (Holman, 1980; Lay, 1963; Saad, 1966) for real gases utilizing molar volume yields:

$$
\frac{p v_{m}}{\mathfrak{R} T}=Z=1+A \frac{p}{\mathfrak{R} T}+B \frac{p^{2}}{\mathfrak{R} T}+C \frac{p^{3}}{\mathfrak{R} T}+\ldots=1+A^{\prime} p+B^{\prime} p^{2}+C^{\prime} p^{3}+\ldots
$$

Here, the universal gas constant is $\Re=8,314.32 \mathrm{~J} /(\mathrm{kmol} \cdot \mathrm{K})$ and the Avogadro number is the familiar $N_{A}=6.022169 \times 10^{26} \mathrm{kmol}^{-1}$. Such virial equation of state was first suggested by Kamerlingh Onnes in 1901 (Lay, 1963; Saad, 1966). For not too high pressures many gases in homogeneous air mixture such as $\mathrm{N}_{2}$ show that compressibility factor stays almost constant and very close to one (Saad, 1974). Thus, for all practical purposes dry atmospheric air follows the ideal- (or perfect-) gas law quite faithfully $(\mathrm{Z}=1)$ until about $86 \mathrm{~km}$. The coefficient of isentropic expansion of perfect dry air is thus a constant $\gamma=c_{p} / c_{v}=1.40$. The real gases will experience disassociation and ionization which leads to changes in chemical and thermodynamic properties.

For the non-interacting ideal-gas mixture, Dalton's and Amagat's law simultaneously apply (Holman, 1980; Lay, 1963; Saad, 1966):

$$
p_{\text {tot }}=\sum_{i=1}^{n} p_{i} \quad v_{\text {tot }}=\sum_{i=1}^{n} v_{i} \Rightarrow \sum_{i=1}^{n} f_{i}=\frac{1}{v_{\text {tot }}} \sum_{i=1}^{n} v_{i}=1
$$


The molecular weight and volume (concentration) fractions of the most abundant gases in the atmosphere are given in Table 2 (NOAA, 1976). The average molecular weight and the particular gas constant of dry air mixture up to about $86 \mathrm{~km}$ is (NOAA, 1976):

$$
\sum_{i=1}^{n} f_{i} M_{i}=M_{0}=28.9644[\mathrm{~kg} / \mathrm{kmol}] \quad R=\frac{\mathfrak{R}}{M_{0}}=287.053\left[\mathrm{~J} \mathrm{~kg}^{-1} \mathrm{~K}^{-1}\right]
$$

However, due to changing molecular weight of the air mixture an ISA standard introduces a molecular scale temperature which is based on the kinetic (thermodynamic) temperature and the ratio of the molecular weights at SL and given altitude. It is this molecular-scale temperature that is given as a function of geopotential altitude in standard atmosphere (NOAA, 1976).

The change of atmospheric pressure with altitude is thus based on the fundamental equation of aerostatics (Granger, 1995) and employs the ideal-gas law:

$d p=-\rho g d z=-\left(\frac{p}{R T}\right) \cdot g(z) \cdot d z$

In the absence of vertical acceleration, the aerostatic (hydrostatic) and thermodynamic pressures are equal (Dutton, 2002). Moreover, it was assumed that aerostatic (thermodynamic) pressure is a function of height only. More details on atmospheric thermodynamics can be found in Dutton (2002).

Table 2

The Molecular Weight and Fractional Volume of the Few Most Important Gas Species in the Dry Atmospheric Air Below $80 \mathrm{~km}$

\begin{tabular}{ccc}
\hline Gas species & $\begin{array}{c}\text { Molecular Weight } \\
M_{i}[\mathrm{~kg} / \mathrm{kmol}]\end{array}$ & $\begin{array}{c}\text { Fractional Volume } \\
f_{i}[-]\end{array}$ \\
\hline $\mathrm{N}_{2}$ & 28.0134 & 0.78084 \\
$\mathrm{O}_{2}$ & 31.9988 & 0.209476 \\
$\mathrm{Ar}$ & 39.948 & 0.00934 \\
$\mathrm{CO}_{2}$ & 44.00995 & 0.000314 \\
\hline$\Sigma$ & & 0.99997 \\
\hline
\end{tabular}


Gravitational acceleration is thus height-dependent and analytic integration becomes more complicated. It is therefore a common practice to introduce the concept of "geopotential altitude" or the height for which the gravitational acceleration stays constant with altitude (Eshelby, 2000; Saucier, 1989). Gravitational potential or geopotential defines the potential energy per unit mass of a particle moving in gravitational field. The basic idea behind geopotential altitude is that reduced gravitational acceleration with increasing MSL altitude will result in an actually longer vertical column of air producing the same surface pressure as a shorter column of air (geopotential height) with constant surface gravity. Geopotential height is always lower than orthometric altitude above the Geoid. The relationship between geopotential altitude $(H)$ and orthometric altitude $(z)$ is:

$d p=-\rho g d z=-\rho g_{0} d H$

or by using Equation 1:

$\left(\frac{R_{0}}{R_{0}+z}\right)^{2} d z=d H$

Integrating Equation 7, one obtains the relationship between constant-g (geopotential) height and the variable-g (orthometric) height above MSL:

$H=\left(\frac{R_{0}}{R_{0}+z}\right) \cdot z \approx\left(1-\frac{z}{R_{0}}\right) \cdot z \quad \frac{z}{R_{0}}<<1 \quad|H| \leq|z|$

For example, when the orthometric altitude is $100 \mathrm{~km}(328,080 \mathrm{ft})$ geopotential altitude is $98.455 \mathrm{~km}(322,931 \mathrm{ft})$ or in linear Taylor approximation $98.43 \%$ of orthometric altitude. For current high-subsonic commercial air transportation typically conducted at $9-12 \mathrm{~km}(30,000$ to $40,000 \mathrm{ft})$ differences between geopotential and orthometric altitude is negligible (less than $0.16 \%$ ). Integration of the differential aerostatic equilibrium (Equation 6) can now be performed easily in terms of geopotential altitude with constant gravitational acceleration. Orthometric altitude can be calculated from the geopotential one as:

$$
z=\left(\frac{R_{0}}{R_{0}-H}\right) \cdot H \approx\left(1+\frac{H}{R_{0}}\right) \cdot H \quad \frac{H}{R_{0}}<<1
$$


Above $86 \mathrm{~km} \mathrm{MSL}$, the physical-chemical processes in Earth's atmosphere become considerably more complicated and relatively simple modeling using the ideal-gas law as presented here is no longer valid (NOAA, 1976).

Total mass of the atmosphere is a fundamental quantity to all atmospheric sciences as emphasized by Trenberth and Smith (2005). By knowing the change of air mass-density with altitude a mass of each particular atmospheric layer $\left(0 \leq z_{1} \leq z \leq z_{2}<\infty\right)$ can be calculated for spherically symmetric Earth (of radius $R_{0}$ ) and atmosphere:

$M(z)=\iiint_{V(z)} \rho(z) d V=4 \pi R_{0}^{2} \rho_{S L} \int_{z_{1}}^{z_{2}} \sigma(z)\left(1+\frac{z}{R_{0}}\right)^{2} d z$

The total atmospheric mass is a sum of fractional masses. Similarly, one can calculate the weight of a given atmospheric layer by knowing the air massdensity distribution and the change of gravitational acceleration, resulting in:

$W(z)=\iiint_{V(z)} \rho(z) g(z) d V=4 \pi R_{0}^{2} g_{0} \rho_{S L} \int_{z_{1}}^{z_{2}} \sigma(z) d z$

These integrals can be evaluated analytically or numerically for each atmospheric layer. Some of the integrals are more complicated than others and cumbersome to work with for different atmospheric layers. Therefore, simple Simpson's numerical integration (Chapra \& Canale, 2006: Press Teulkolsky Vetterling \& Flanery, 1992) will be used instead. According to Davies (2003), the mass of the atmosphere is about $5.2 \times 10^{18} \mathrm{~kg}$. The mass of the oceans is about $1.3 \times 10^{21} \mathrm{~kg}$ and the mass of the Earth is almost $6 \times 10^{24} \mathrm{~kg}$. Thus, Earth is more than a million times more massive than its atmosphere and its oceans which occupy about $70 \%$ of Earth's surface, although relatively shallow, are about 260 times more massive than the atmosphere. Trenberth and Smith (2005), reported the dry mass of the atmosphere to be $(5.1352 \pm 0.0003) \times 10^{18} \mathrm{~kg}$ while average water vapor mass is $1.27 \times 10^{16} \mathrm{~kg}$. Total mean mass of the atmosphere is then $5.1480 \times 10^{18} \mathrm{~kg}$ with the global mean surface pressure of $985.5 \mathrm{hPa}$. These values were based on globally measured surface pressures. Mass and weight of Earth's atmosphere are directly proportional to surface pressure (Trenberth \& Smith, 2005). 


\section{ISA Atmospheric Models}

Two basic ISA models of molecular-scale temperature change exist in the standard atmosphere:

- Isothermal (constant temperature or zero TLR)

- Linear (constant positive or negative TLR).

A graphical illustration of temperatures bands in standard atmosphere calculations are shown in Figure 2. The calculated base layer pressures, temperatures, and densities, starting with the given SL standard are presented in Table 3 for each corresponding geopotential altitude.

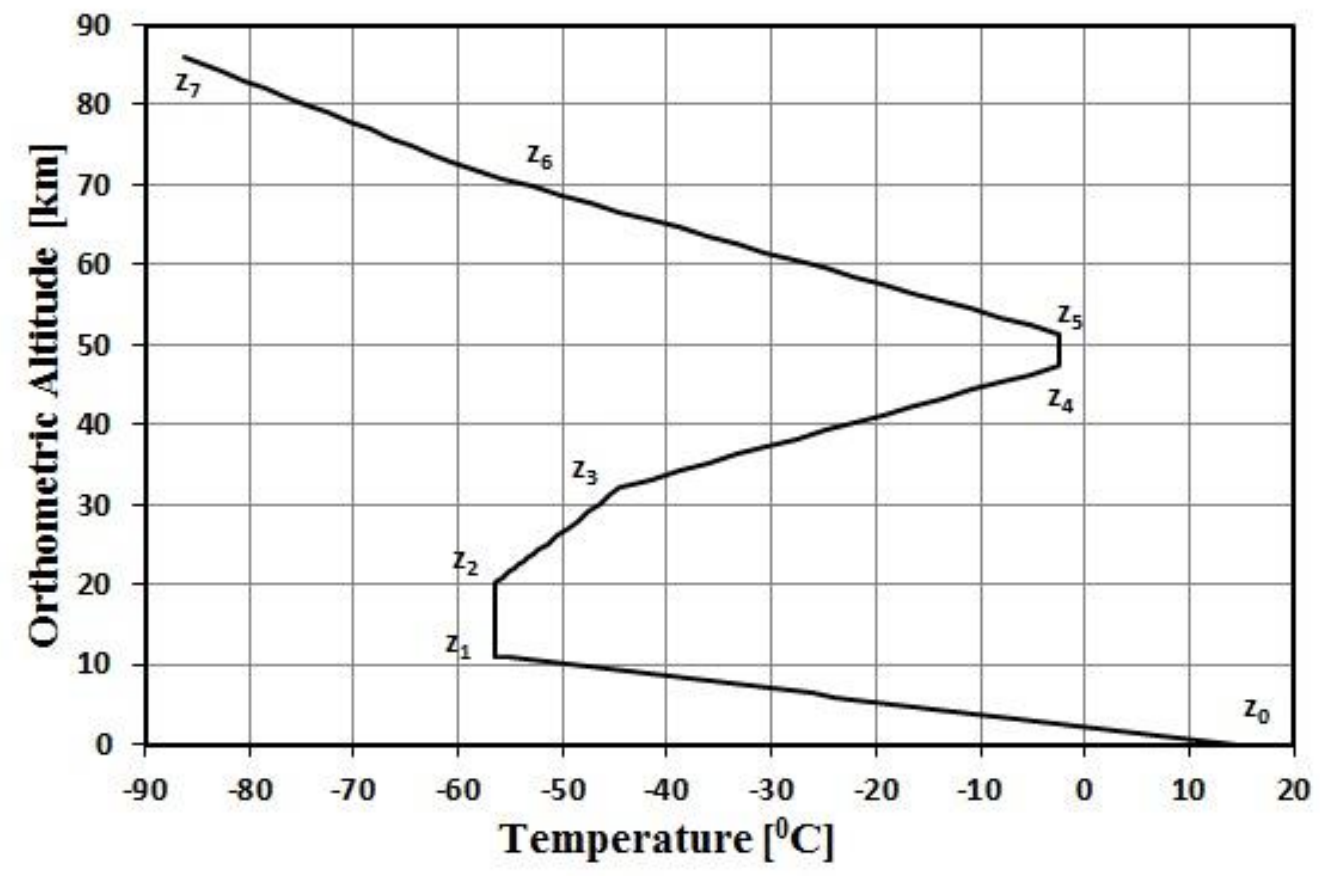

Figure 2. Temperature distribution of ISA below $86 \mathrm{~km} \mathrm{MSL.}$

For constant TLR homosphere (troposphere, stratosphere, and mesosphere), changes in atmospheric pressure with geopotential height follows differential law:

$$
\frac{d p}{p}=-\left(\frac{g_{0}}{R T}\right) d H=-\left(\frac{g_{0}}{R \alpha}\right) \frac{d T}{T} \quad \alpha \equiv \frac{d T}{d H}=\text { const }
$$


Troposphere is the lowest thermal gradient layer of ISA atmosphere characterized by the constant negative TLR:

$$
\left(\frac{d T}{d H}\right)_{0}=\alpha_{0}=-0.0065 \mathrm{~K} / \mathrm{m} \approx-1.981224^{0} \mathrm{C} /(1000 \mathrm{ft}) \approx-0.00356^{0} \mathrm{~F} / \mathrm{ft}
$$

In troposphere temperatures change linearly with geopotential altitude up to $11 \mathrm{~km}$ or $36,089 \mathrm{ft}\left(h_{S L} \leq h \leq h_{1}(=11 \mathrm{~km})\right)$ :

$$
T=T_{S L}+\alpha_{0} \cdot\left(H-H_{S L}\right) \Rightarrow \theta=\frac{T}{T_{S L}}=1+\frac{\alpha_{0}}{T_{S L}}\left(H-H_{S L}\right) \quad H_{S L}=0
$$

In terms of orthometric altitude that would be from 0 to $11,019 \mathrm{~m}(36,151$ $\mathrm{ft})$. Integration of Equation 12 results in:

$$
\int_{p_{S L}}^{p} \frac{d p}{p}=-\left(\frac{g_{0}}{R \alpha_{0}}\right)_{T_{S L}}^{T} \frac{d T}{T} \Rightarrow \frac{p}{p_{S L}}=\delta=\left(\frac{T}{T_{S L}}\right)^{-g_{0} / R \alpha_{0}}=\theta^{-\lambda_{0}}
$$

Specifically, for troposphere, the non-dimensional exponent of linear atmosphere becomes:

$$
\lambda_{0}=\frac{g_{0}}{R \alpha_{0}}=\frac{9.80665}{287.053 \cdot(-0.0065)}=-5.2558774 \approx-5.256
$$

Non-dimensional ideal-gas law is expressed as:

$$
\frac{p}{p_{S L}}=\frac{\rho R T}{\rho_{S L} R T_{S L}}=\frac{\rho}{\rho_{S L}} \frac{T}{T_{S L}} \Rightarrow \delta=\sigma \cdot \theta
$$

Air density changes in constant lapse-rate layer according to the ideal-gas law as:

$$
\sigma=\frac{\rho}{\rho_{S L}}=\frac{\delta}{\theta}=\left(\frac{T}{T_{S L}}\right)^{-g_{0} / R \alpha_{0}} \cdot\left(\frac{T_{S L}}{T}\right)=\theta^{-\lambda_{0}-1}
$$


Table 3

Base Values of Dimensional Air Temperature, Pressure and Density for Each Standard Atmospheric Temperature Layer

\begin{tabular}{cccccc}
\hline Layer & $\begin{array}{c}\text { Geopotential } \\
\text { Altitude }[\mathrm{km}]\end{array}$ & $\begin{array}{c}\text { Orthometric } \\
\text { Altitude }[\mathrm{km}]\end{array}$ & $T[\mathrm{~K}]$ & $p[\mathrm{~Pa}]$ & $\rho\left[\mathrm{kg} / \mathrm{m}^{3}\right]$ \\
\hline 0 & 0 & 0 & 288.15 & $1.0132500 \mathrm{E}+05$ & $1.2250000 \mathrm{E}+00$ \\
1 & 11 & 11.019 & 216.65 & $2.2632064 \mathrm{E}+04$ & $3.6391803 \mathrm{E}-01$ \\
2 & 20 & 20.063 & 216.65 & $5.4748887 \mathrm{E}+03$ & $8.8034864 \mathrm{E}-02$ \\
3 & 32 & 32.1615 & 228.65 & $8.6801868 \mathrm{E}+02$ & $1.3225009 \mathrm{E}-02$ \\
4 & 47 & 47.349 & 270.65 & $1.1090631 \mathrm{E}+02$ & $1.4275335 \mathrm{E}-03$ \\
5 & 51 & 51.412 & 270.65 & $6.6938873 \mathrm{E}+01$ & $8.6160551 \mathrm{E}-04$ \\
6 & 71 & 71.800 & 214.65 & $3.9564204 \mathrm{E}+00$ & $6.4211031 \mathrm{E}-05$ \\
7 & 84.852 & 86.0 & 186.95 & $3.7338359 \mathrm{E}-01$ & $6.9578835 \mathrm{E}-06$ \\
\hline
\end{tabular}

An isothermal temperature layer (tropopause, stratopause, etc.) follows differential law:

$\frac{d p}{p}=-\left(\frac{g_{0}}{R T}\right) d H \quad T=$ const $\quad \frac{d T}{d H}=0$

After integration for geopotential height range (e.g., tropopause) one obtains:

$$
\int_{p_{1}}^{p} \frac{d p}{p}=-\left(\frac{g_{0}}{R T_{1}}\right) \int_{H_{1}}^{H} d H \Rightarrow \frac{p}{p_{1}}=\frac{p}{p_{S L}} \frac{p_{S L}}{p_{1}}=\delta \frac{p_{S L}}{p_{1}}=\frac{\delta}{\delta_{1}}
$$

and

$$
\delta_{1-2}(H)=\delta_{1} \cdot \exp \left[-\kappa_{1}\left(H-H_{1}\right)\right] \quad H_{1}<H \leq H_{2}(=20 \mathrm{~km})
$$

The coefficient of isothermal atmosphere (specifically tropopause here):

$$
\kappa_{1}=\frac{g_{0}}{R T_{1}}=\frac{g_{0}}{R T_{2}}=\frac{9.80665}{287.053 \cdot 216.65}=1.57688 \times 10^{-4} \mathrm{~m}^{-1}
$$

Base pressure of particular layers can be found in Table 3. Each base layer is calculated as a top from the previous layer, yielding in this particular case: 


$$
p_{1}=p_{S L} \theta_{1}^{-g_{0} / R \alpha_{0}}=22,632.1 \Rightarrow \delta_{1}=\frac{p_{1}}{p_{S L}}=0.22336111
$$

Density change function can be calculated from:

$$
\frac{p}{p_{1}}=\frac{\rho R T}{\rho_{1} R T}=\frac{\rho}{\rho_{1}} \Rightarrow \sigma=\sigma_{1} \cdot \exp \left[-\kappa_{1}\left(H-H_{1}\right)\right]
$$

Density of the preceding base is calculated using appropriate models, for example, the top of the first layer, $\sigma_{1}=\rho_{1} / \rho_{S L}=\theta_{1}^{-\lambda_{0}-1}$. There can be no discontinuity in values at the interface of two layers. However, rates of change may not be continuous across layers and that is particularly true for ISA's vertical temperature distribution.

Stratosphere is the second major thermal layer of ISA atmosphere and is characterized by three different TLRs (sublayers). The first one is the familiar zero TLR tropopause and the two upper layers with positive TLRs (from 20 to 32 and 32 to 47 geopotential $\mathrm{km}$ ):

$$
\begin{aligned}
& \left(\frac{d T}{d H}\right)_{2}=\alpha_{2}=+0.001 \mathrm{~K} / \mathrm{m} \approx+0.30488^{0} \mathrm{C} /(1000 \mathrm{ft})=+0.0005488^{\circ} \mathrm{F} / \mathrm{ft} \\
& \left(\frac{d T}{d H}\right)_{3}=\alpha_{3}=+0.0028 \mathrm{~K} / \mathrm{m} \approx+0.85366^{0} \mathrm{C} /(1000 \mathrm{ft})=+0.001536^{\circ} \mathrm{F} / \mathrm{ft}
\end{aligned}
$$

Temperature increases linearly with geopotential altitude in Stratosphere II and Stratosphere III models:

$$
\begin{array}{ll}
T_{2-3}=T_{2}+\alpha_{2} \cdot\left(H-H_{2}\right) \Rightarrow \frac{T}{T_{2}}=1+\frac{\alpha_{2}}{T_{2}}\left(H-H_{2}\right) & H_{2} \leq H \leq H_{3}(=32 \mathrm{~km}) \\
T_{3-4}=T_{3}+\alpha_{3} \cdot\left(H-H_{3}\right) \Rightarrow \frac{T}{T_{3}}=1+\frac{\alpha_{3}}{T_{3}}\left(H-H_{3}\right) & H_{3} \leq H \leq H_{4}(=47 \mathrm{~km})
\end{array}
$$

A condition $T_{2-3}\left(H_{3}\right)=T_{3-4}\left(H_{3}\right)$ must be satisfied. Integration of Equation 12 with the new positive lapse rate in the stratospheric region 2-3, results in: 


$$
\begin{aligned}
& \int_{p_{2}}^{p} \frac{d p}{p}=-\left(\frac{g_{0}}{R \alpha_{2}}\right)_{T_{2}}^{T} \frac{d T}{T} \Rightarrow \\
& \frac{p}{p_{2}}=\frac{p}{p_{S L}} \frac{p_{S L}}{p_{1}} \frac{p_{1}}{p_{2}}=\delta \frac{p_{S L}}{p_{1}} \frac{p_{1}}{p_{2}}=\left(\frac{T}{T_{2}}\right)^{-g_{0} / R \alpha_{2}}=\left(\frac{T}{T_{S L}} \frac{T_{S L}}{T_{1}} \frac{T_{1}}{T_{2}}\right)^{-\lambda_{2}}
\end{aligned}
$$

The pressure change in the middle stratospheric layer is thus:

$$
\delta_{2-3}=\left(\frac{p_{1}}{p_{S L}}\right) \cdot\left(\frac{p_{2}}{p_{1}}\right) \cdot\left(\frac{T_{1}}{T_{2}}\right)^{-\lambda_{2}}\left(\frac{T}{T_{S L}}\right)^{-\lambda_{2}}\left(\frac{T_{S L}}{T_{1}}\right)^{-\lambda_{2}}=\left[\frac{\delta_{1} \cdot \delta_{2}}{\left(\theta_{1} \cdot \theta_{2}\right)^{-\lambda_{2}}}\right] \cdot \theta^{-\lambda_{2}}
$$

A similar expression could be given for density change, but it is much easier to just invoke the ideal gas law. The analog procedure is performed for the linear stratospheric-III layer resulting in dimensionless pressure:

$$
\delta_{3-4}(H)=\left[\frac{\delta_{1} \cdot \delta_{2} \cdot \delta_{3}}{\left(\theta_{1} \cdot \theta_{2} \cdot \theta_{3}\right)^{-\lambda_{3}}}\right] \cdot \theta^{-\lambda_{3}}
$$

and corresponding density:

$$
\sigma_{3-4}(H)=\frac{\rho_{3-4}}{\rho_{S L}}=\frac{\delta_{3-4}}{\theta_{3-4}}=\left[\frac{\delta_{1} \cdot \delta_{2} \cdot \delta_{3}}{\left(\theta_{1} \cdot \theta_{2} \cdot \theta_{3}\right)^{-\lambda_{3}}}\right] \cdot \theta^{-\lambda_{3}-1}
$$

The next standard temperature layer is the stratopause (part of Mesosphere) which is just another isothermal layer with:

$$
\delta_{4-5}(H)=\delta_{1} \cdot \delta_{2} \cdot \delta_{3} \cdot \delta_{4} \cdot \exp \left[-\kappa_{4} \cdot\left(H-H_{4}\right)\right] \quad H_{4}<H \leq H_{5}(=51 \mathrm{~km})
$$

A general model can now be devised about the form of non-dimensional pressure equations. If the atmospheric layer is with the linear temperature lapserate, then for the $\mathrm{n}$-th layer, one may write:

$$
\delta_{n}(H)=\frac{\left(\prod_{i=1}^{n-1} \delta_{i}\right)}{\left(\prod_{i=1}^{n-1} \theta_{i}\right)^{-\lambda_{n}}} \cdot \theta^{-\lambda_{n}} \quad \lambda_{n} \equiv \frac{g_{0}}{R \cdot\left(\frac{d T}{d H}\right)_{n}}=\frac{g_{0}}{R \cdot \alpha_{n}}=\text { const }[-]
$$


If the n-th homospheric layer is isothermal with the known base layer height of $H_{n B}$, then:

$$
\delta_{n}(H)=\left(\prod_{i=1}^{n-1} \delta_{i}\right) \cdot \exp \left[-\kappa_{n}\left(H-H_{n B}\right)\right] \quad \kappa_{n} \equiv \frac{g_{0}}{R \cdot T_{n}}=\text { const }\left[\mathrm{m}^{-1}\right]
$$

Non-dimensional ISA temperatures in an n-th layer is calculated for constant-TLR $\left(\alpha_{n}\right)$ or constant temperature (isothermal) as a function of altitude:

constant $-\mathrm{TLR}: \quad \theta_{n}(H)=\left(\prod_{i=1}^{n-1} \theta_{i}\right) \cdot\left[1+\frac{\alpha_{n}}{T_{n B}}\left(H-H_{n B}\right)\right]$

isothermal : $\theta_{n}(H)=\left(\prod_{i=1}^{n-1} \theta_{i}\right) \cdot 1$

Where

$T_{n B}=\left(\prod_{i=1}^{n-1} \theta_{i}\right) \cdot T_{S L}$

Values of characteristic exponents for the linear and the isothermal atmospheric layers are summarized in Table 4. Dimensionless pressure and temperature changes (linear or constant) for a particular layer are expressed as $\delta_{i}=p_{i} / p_{i-1}<1$ and $\theta_{i}=T_{i} / T_{i-1} \leq \geq 1$. Base values of non-dimensional parameters for each standard atmospheric temperature layer are summarized in Table 5. Equations 28 to 31 together with Tables 4 and 5 represent some of the main contributions of this work.

Non-dimensional air mass density for a given layer is simply obtained from dimensionless ideal-gas law $\sigma_{n}(H)=\delta_{n}(H) / \theta_{n}(H)$, which in the case of linear atmosphere, the ISA mass-density is:

$$
\sigma_{n}(H)=\frac{\left(\prod_{i=1}^{n-1} \delta_{i}\right)}{\left(\prod_{i=1}^{n-1} \theta_{i}\right)^{-\lambda_{n}}} \cdot \theta^{-\lambda_{n}-1}
$$


Table 4

The Values of Exponents and Scale Heights for Linear and Isothermal Layers in ISA Calculations

\begin{tabular}{cccc}
\hline $\begin{array}{c}\text { Temperature } \\
\text { Layer }\end{array}$ & $\lambda_{n}=\frac{g_{0}}{R \cdot \alpha_{n}}[-]$ & $\kappa_{n}=\frac{g_{0}}{R \cdot T_{n}}\left[\mathrm{~m}^{-1}\right]$ & $H_{n}^{*}=\frac{R \cdot T_{n}}{g_{0}}[\mathrm{~m}]$ \\
\hline $0-1$ & -5.2558761 & --- & --- \\
$1-2$ & --- & 0.00015769 & $6,341.56$ \\
$2-3$ & 34.1631947 & --- & --- \\
$3-4$ & 12.201141 & --- & --- \\
$4-5$ & --- & 0.00012623 & $7,922.05$ \\
$5-6$ & -12.201141 & --- & --- \\
$6-7$ & -17.081597 & --- & --- \\
\hline
\end{tabular}

Clearly, complicated and cumbersome computations are required as the next higher atmospheric layer is calculated which is however, facilitated by using the base values for each layer in combination with the corresponding ISA-layer law. Basic SL ISA properties of dry air mixture are given in Table 6. Dimensional and non-dimensional speed of sound or acoustic speed or propagation speed of small isentropic pressure disturbances is calculated for each ISA layer from:

$$
\chi=\frac{a}{a_{S L}}=\frac{\sqrt{\gamma R T}}{\sqrt{\gamma R T_{S L}}}=\left(\frac{T}{T_{S L}}\right)^{1 / 2}=\theta^{1 / 2}
$$

Dimensionless dynamic and kinematic viscosity coefficients are:

$$
\xi=\frac{\mu}{\mu_{S L}}=\frac{v \cdot \rho}{v_{S L} \cdot \rho_{S L}}=\varsigma \cdot \sigma \quad \varsigma=\frac{v}{v_{S L}}
$$

Approximate relationship for dynamic and kinematic viscosity of air with surprisingly good accuracy at lower temperatures is given by Granger (1995):

$$
\xi=\theta^{0.76} \quad \varsigma=\frac{\xi}{\sigma}=\frac{\theta^{1.76}}{\delta}
$$

Graphical representation of calculated essential non-dimensional ISA air parameters are shown in Figure 3. McCormick (1995) gives an expression for 
kinematic viscosity (in $\mathrm{ft}^{2} / \mathrm{s}$ ) which is accurate within $0.1 \%$ compared to ISA values up to $70,000 \mathrm{ft}(21.3 \mathrm{~km})$ :

$$
v(z)=\sum_{n=0}^{7} A_{n} \cdot\left(\frac{z}{1000}\right)^{n} \quad\left[10^{4} \mathrm{ft}^{2} / \mathrm{s}\right]
$$

Coefficients of A are:

$$
\begin{array}{lc}
A_{0}= & 1.5723 \\
A_{1}= & 8.73065 \times 10^{-2} \\
A_{2}= & -1.184112 \times 10^{-2} \\
A_{3}= & 1.1697 \times 10^{-3} \\
A_{4}= & -5.2720 \times 10^{-5} \\
A_{5}= & 1.22466 \times 10^{-6} \\
A_{6}= & -1.369780 \times 10^{-8} \\
A_{7}= & 5.94238 \times 10^{-11}
\end{array}
$$

Table 5

Base Values of Non-dimensional Parameters for Each Standard Atmospheric Temperature Layer

\begin{tabular}{ccccc}
\hline $\begin{array}{c}\text { n-th } \\
\text { Layer }\end{array}$ & $\begin{array}{c}\text { Geopotential } \\
\text { Altitude }[\mathrm{km}]\end{array}$ & $\theta_{n}=\frac{T_{n}}{T_{n-1}}$ & $\delta_{n}=\frac{p_{n}}{p_{n-1}}$ & $\sigma_{n}=\frac{\rho_{n}}{\rho_{n-1}}$ \\
\hline 0 & 0 & $1.0000000 \mathrm{E}+00$ & $1.0000000 \mathrm{E}+00$ & $1.0000000 \mathrm{E}+00$ \\
1 & 11 & $7.5186535 \mathrm{E}-01$ & $2.2336111 \mathrm{E}-01$ & $2.9707594 \mathrm{E}-01$ \\
2 & 20 & $1.0000000 \mathrm{E}+00$ & $2.4190850 \mathrm{E}-01$ & $2.4190850 \mathrm{E}-01$ \\
3 & 32 & $1.0553889 \mathrm{E}+00$ & $1.5854545 \mathrm{E}-01$ & $1.5022467 \mathrm{E}-01$ \\
4 & 47 & $1.1836869 \mathrm{E}+00$ & $1.2776949 \mathrm{E}-01$ & $1.0794197 \mathrm{E}-01$ \\
5 & 51 & $1.0000000 \mathrm{E}+00$ & $6.0356237 \mathrm{E}-01$ & $6.0356237 \mathrm{E}-01$ \\
6 & 71 & $7.9309071 \mathrm{E}-01$ & $5.9104975 \mathrm{E}-02$ & $7.4524861 \mathrm{E}-02$ \\
7 & 84.852 & $8.7093408 \mathrm{E}-01$ & $9.4374093 \mathrm{E}-02$ & $1.0835963 \mathrm{E}-01$ \\
\hline
\end{tabular}

Values of kinematic viscosity in McCormick's approximation can be easily transformed into SI system (International System of units) using $\mathrm{m}^{2} / \mathrm{s}$ by multiplying $\mathrm{ft}^{2} / \mathrm{s}$ value by $(0.3048)^{2}$. Changes of kinematic viscosity with altitude has drastic implications on a wing's Reynolds number. At very high altitudes 
(above 180,000 ft), Reynolds numbers decreases by about two orders-ofmagnitude, compared to SL values, chiefly because kinematic viscosity increases. This seriously affects aerodynamic and stability coefficients. A graphical depiction of several dynamic and kinematic viscosity models versus orthometric altitude are shown in Figure 4. Viscosity model given in Granger (1995) is in excellent agreement with the ISA while McCormick's (1995) least-square approximation of tabular ISA values shows increasing discrepancies above about $22 \mathrm{~km}$ as was also suggested by the original author.

Table 6

Properties of Air at Base SL as Defined by ISA

\begin{tabular}{|c|c|c|}
\hline & SI Units & $\begin{array}{l}\text { British/American } \\
\text { Engineering Units }\end{array}$ \\
\hline Pressure, $p_{S L}$ & $\begin{array}{l}1.01325 \times 10^{5} \mathrm{~N} / \mathrm{m}^{2} \\
760 \mathrm{~mm} \mathrm{Hg}\end{array}$ & $\begin{array}{l}2116.22 \mathrm{lb} / \mathrm{ft}^{2} \\
14.696 \mathrm{lb} / \text { inch }^{2}(\mathrm{psi}) \\
29.92 \text { inch } \mathrm{Hg}\end{array}$ \\
\hline Temperature, $T_{S L}$ & $\begin{array}{l}288.15 \mathrm{~K} \\
15^{\circ} \mathrm{C}\end{array}$ & $\begin{array}{l}518.67^{0} \mathrm{R} \\
59^{0} \mathrm{~F}\end{array}$ \\
\hline Density, $\rho_{S L}$ & $1.225 \mathrm{~kg} / \mathrm{m}^{3}$ & $0.0023769 \mathrm{slug} / \mathrm{ft}^{3}$ \\
\hline Speed of sound, $a_{S L}$ & $340.294 \mathrm{~m} / \mathrm{s}$ & $1116.437 \mathrm{ft} / \mathrm{s}$ \\
\hline Gas constant, $R$ & $287.053 \mathrm{~J} / \mathrm{kg} \mathrm{K}$ & $1716 \mathrm{ft} \times \mathrm{lb} / \mathrm{slug}{ }^{0} \mathrm{R}$ \\
\hline Dynamic viscosity, $\mu_{S L}$ & $\begin{array}{l}1.78936 \times 10^{-5} \mathrm{~Pa} \cdot \mathrm{s} \\
1.78936 \times 10^{-2} \mathrm{cP}\end{array}$ & $3.7372 \times 10^{-7} \mathrm{lbf} \times \mathrm{s} / \mathrm{ft}^{2}$ \\
\hline Kinematic viscosity $v_{S L}$ & $\begin{array}{l}1.4607 \times 10^{-5} \mathrm{~m}^{2} / \mathrm{s} \\
1.4607 \times 10^{-3} \mathrm{cSt}\end{array}$ & $1.5723 \times 10^{-4} \mathrm{ft}^{2} / \mathrm{s}$ \\
\hline
\end{tabular}

By knowing the standard SL-values it is simple to compute the actual air temperature, pressure, density, speed of sound, and viscosities at given altitude:

$T(z)=\theta(z) \cdot T_{S L} \quad p(z)=\delta(z) \cdot p_{S L} \quad \rho(z)=\sigma(z) \cdot \rho_{S L}$

The derived physical variables from the fundamental three are: 


$$
\begin{aligned}
& a(z)=\chi(z) \cdot a_{S L}=\theta^{0.5} \cdot a_{S L} \\
& \mu(z)=\xi(z) \cdot \mu_{S L}=\theta^{0.76} \cdot \mu_{S L} \quad v(z)=\varsigma(z) \cdot v_{S L}=\frac{\theta^{1.76}}{\delta} \cdot v_{S L}
\end{aligned}
$$

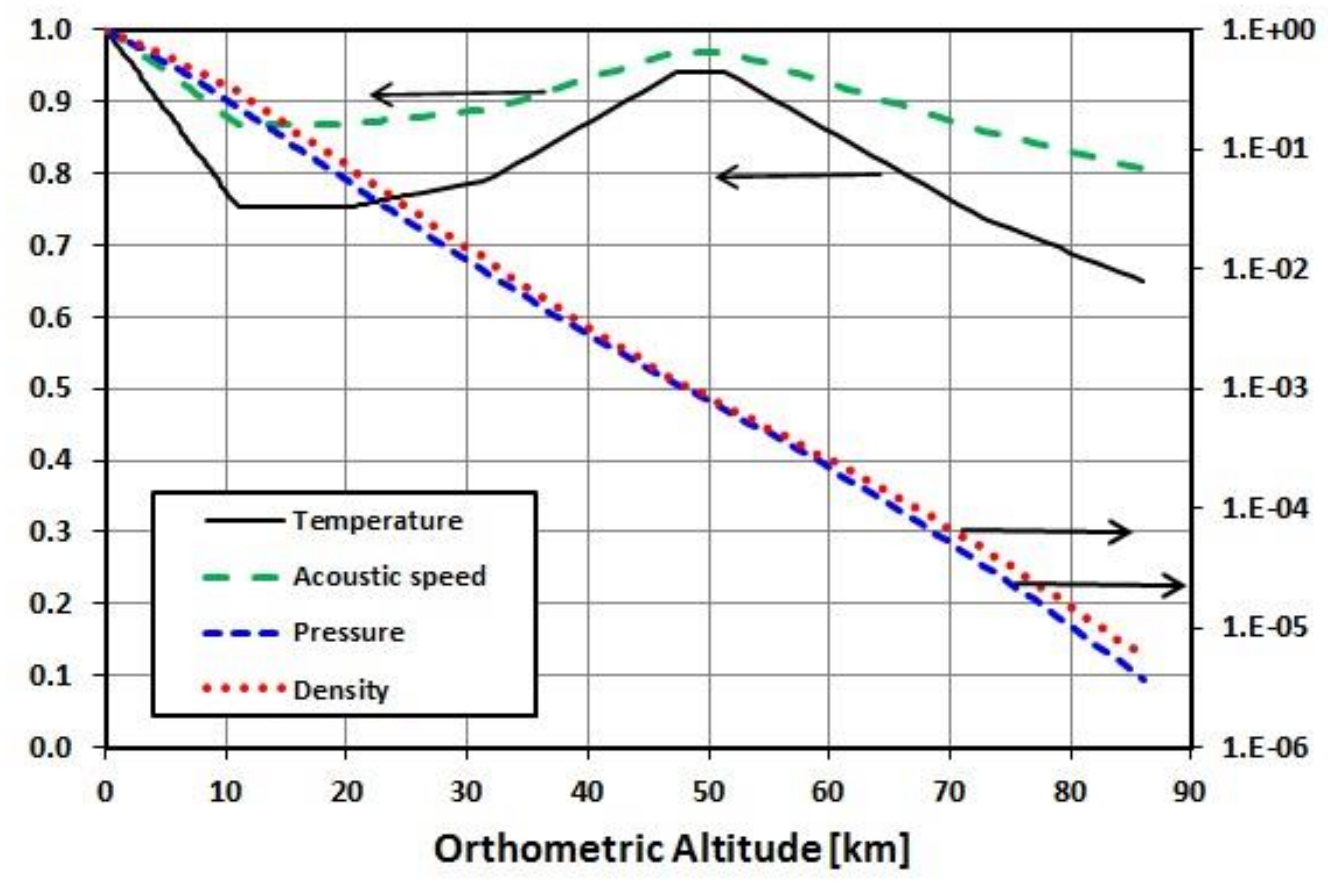

Figure 3. Non-dimensional temperature, pressure, density and speed of sound coefficients in ISA. Dimensionless pressure and density coefficients are shown in logarithmic scale.

\section{Mass and Scale Heights of ISA}

Although the integrals presented in Equations 10 and 11 can be solved analytically, computations are tedious and cumbersome. Instead one could resort to a simple yet quite accurate multi-interval (extended) Simpson's 1/3 integration rule which is step above the trapezoidal integration. Simpson's rule is based on integrating the forward Newton-Gregory interpolating polynomial between three known (measured) values. The accuracy of the Simpson's 1/3 rule is excellent for most of the applications and "well-behaving" functions. It is especially useful when the numerical values of functions to be integrated is given in equidistant intervals. Of course, many other open (suited for improper integrals) or closed (Newton-Cotes) numerical integration methods are available (Chapra \& Canale, 
2006; Press et al., 1992). Accordingly, the mass of an arbitrary ISA layer (a-b) can be approximated with:

$M_{a-b}(z)=4 \pi R_{0}^{2} \rho_{S L} \int_{a}^{b} \sigma(z)\left(1+\frac{z}{R_{0}}\right)^{2} d z=4 \pi R_{0}^{2} \rho_{S L} \int_{a}^{b} f(z) d z$

Where for $a=z_{0}=0$ and $b=z_{n}=86 \mathrm{~km}$ :

$\int_{a}^{b} f(z) d z \approx \frac{(b-a)}{3 n}\left[f\left(z_{0}\right)+4 \sum_{j=1,3,4}^{n-1} f\left(z_{j}\right)+2 \sum_{j=2,4,6}^{n-2} f\left(z_{j}\right)+f\left(z_{n}\right)\right]$

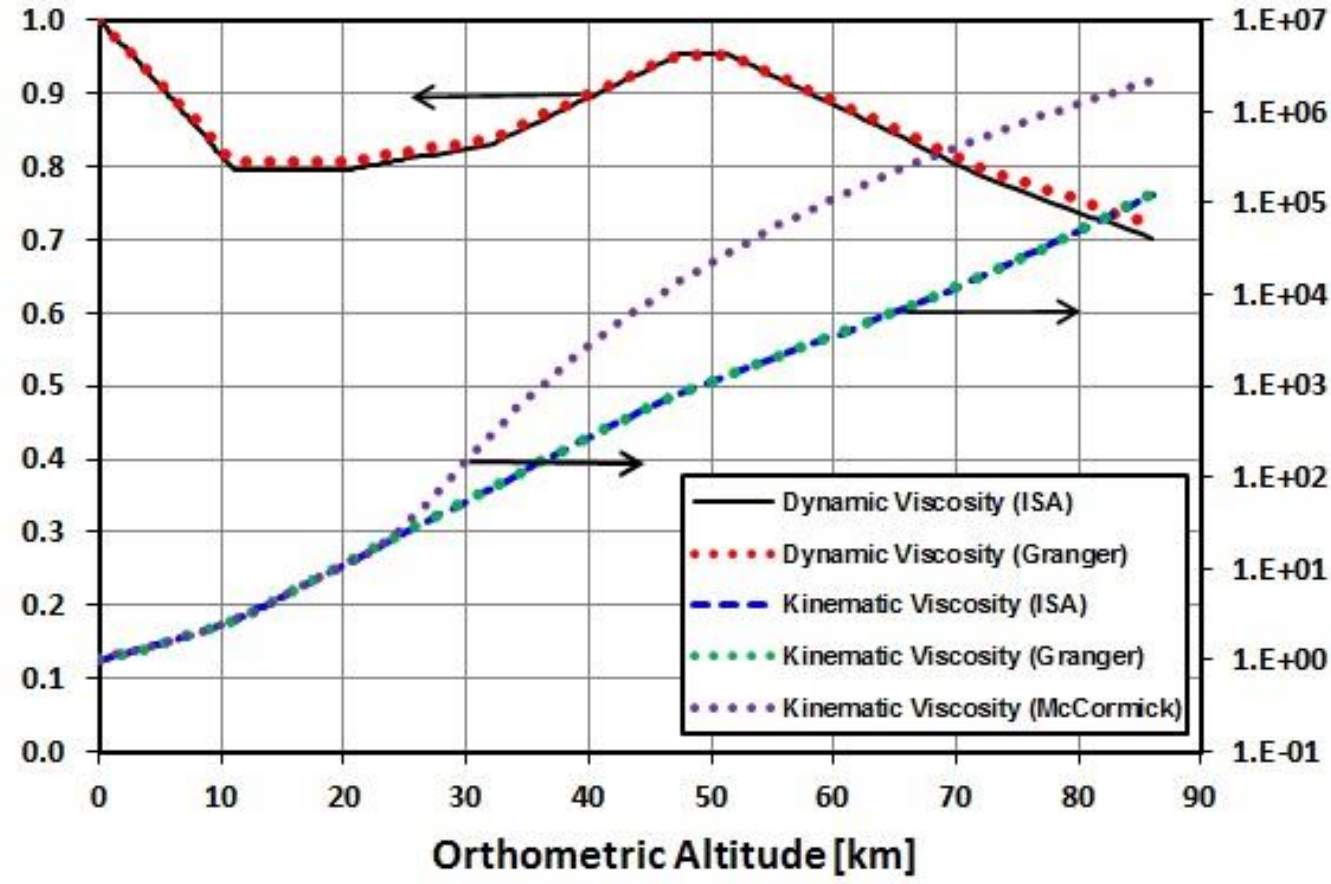

Figure 4. Comparison of non-dimensional ISA dynamic and kinematic viscosities with the models of Granger and McCormick up to 86 orthometric km.

Similarly, weight of each ISA layer is calculated using the same Simpson's numerical integration method. Recall that gravitational attraction will decrease with height resulting in bias toward lower layers. For numerical integration equidistant steps of $100 \mathrm{~m}$ in troposphere were used while starting from the tropopause and all the way up to $86 \mathrm{~km}$ orthometric vertical step of 250 
$\mathrm{m}$ was used. About $77.5 \%$ of the entire ISA atmosphere is contained in the troposphere thus requiring the highest resolution. Masses of each ISA layer and the total ISA mass up to $86 \mathrm{~km}$ is presented in Table 7 based on numerical integration results. The ISA mass and weight have been calculated here for the first time to the best of author's knowledge. Values obtained here are very close to known estimates of true Earth's atmospheric mass.

Table 7

Masses and Weights of ISA Layers

\begin{tabular}{cccc}
\hline ISA Level & $\begin{array}{c}\text { Geopotential } \\
\text { Height }[\mathrm{km}]\end{array}$ & Mass [kg] & Weight [N] \\
\hline Troposphere & $0-11$ & $4.104397 \mathrm{E}+18$ & $4.019439 \mathrm{E}+19$ \\
Tropopause (SS I) & $11-20$ & $9.005369 \mathrm{E}+17$ & $8.791172 \mathrm{E}+18$ \\
Stratosphere II & $20-32$ & $2.432901 \mathrm{E}+17$ & $2.367763 \mathrm{E}+18$ \\
Stratosphere III & $32-47$ & $4.030482 \mathrm{E}+16$ & $3.906894 \mathrm{E}+17$ \\
Stratopause (MS I) & $47-51$ & $2.358320 \mathrm{E}+15$ & $2.277404 \mathrm{E}+16$ \\
Mesosphere II & $51-71$ & $3.396125 \mathrm{E}+15$ & $3.270953 \mathrm{E}+16$ \\
Mesosphere III & $71-84.852$ & $1.960204 \mathrm{E}+14$ & $1.876950 \mathrm{E}+15$ \\
\hline TOTAL & --- & $5.294480 \mathrm{E}+18$ & $5.180137 \mathrm{E}+19$ \\
\hline
\end{tabular}

From values obtained by integration and the total ISA mass up to $86 \mathrm{~km}$, the fractional atmospheric masses have respective scale heights summarized in Table 8.

Table 8

Orthometric Scale Heights of ISA's Mass Fractions

\begin{tabular}{ccc}
\hline ISA Mass fraction & $\begin{array}{c}\text { Orthometric height } \\
{[\mathrm{m}]}\end{array}$ & $\begin{array}{c}\text { Orthometric height } \\
{[\mathrm{ft}]}\end{array}$ \\
\hline $50 \%$ & 5,405 & 17,731 \\
$75 \%$ & 10,216 & 33,518 \\
$90 \%$ & 16,040 & 52,625 \\
$95 \%$ & 20,315 & 66,648 \\
$99 \%$ & 30,899 & 101,374 \\
$99.9 \%$ & 47,857 & 157,009 \\
\hline
\end{tabular}


Calculated scale-heights are accurate within about $\pm 1 \%$ (about $\pm 50 \mathrm{~m}$ in ISA troposphere) and the values were not interpolated, but taken as closest to tabulated fractional mass. For many practical purposes mass of the atmosphere above $86 \mathrm{~km}$ is negligible compared to the total sum over the lower levels. To facilitate the computations, Table A1 of the basic non-dimensional thermodynamic properties calculated with 14 significant digits is given in the Appendix. Typically, only seven significant figures are presented which is more than sufficient for most applications. Least accurate physical constant limits the accuracy of calculations and the numbers of significant digits. The result for altitudes in SI systems can be easily converted to British engineering units still used in some parts of the world.

\section{Discussion of Results}

An example using the new computational model of ISA will be now provided. A task is to calculate ISA temperature, pressure, and density at 40,000 $\mathrm{m}$. The layer identified from Table 1 is stratosphere III (between 32 and $47 \mathrm{~K}$ ) with the constant TLR of $+0.0028 \mathrm{~K} / \mathrm{m}$. Base temperatures, pressures and densities can be found in Table 3, but we will calculate them using the equations derived here. The base temperature is calculated from Equation 31 and using the exponents and base values of layers from Table 4 and 5 (only to five significant digits precision), resulting in:

$\theta_{1}=0.7518 \quad \theta_{2}=1.0000 \quad \theta_{3}=1.0554 \quad \delta_{1}=0.2234 \quad \delta_{2}=0.2419 \quad \delta_{3}=0.1585$

$T_{4 B}=\left(\prod_{i=1}^{4-1} \theta_{i}\right) \cdot T_{S L}=\theta_{1} \times \theta_{2} \times \theta_{3} \times 288.15 \approx 228.65$

Temperature in the $4^{\text {th }}$ layer at $40 \mathrm{~km}$ is calculated from Equation 30 for constant TLR atmosphere:

$$
\theta_{4}=\left(\prod_{i=1}^{3} \theta_{i}\right)\left[1+\frac{\alpha_{4}}{T_{n B}}\left(H-H_{n B}\right)\right] \approx 0.7934 \cdot\left[1+\frac{0.0028}{228.65}(40-32) \times 10^{3}\right]=0.8711
$$

The non-dimensional pressure at $40 \mathrm{~km}$ is calculated utilizing Equation 28 and value of exponent from Table 4:

$$
\delta_{4}(H)=\frac{\delta_{1} \cdot \delta_{2} \cdot \delta_{3}}{\left(\theta_{1} \cdot \theta_{2} \cdot \theta_{3}\right)^{-12.2}} \cdot \theta_{4}^{-12.2}=\frac{0.2234 \times 0.2419 \times 0.1585}{(0.7518 \times 1.0 \times 1.0554)^{-12.2}} \times 0.8711^{-12.2} \approx 0.002742
$$


Air density at $40 \mathrm{~km}$ can be simply calculated utilizing the ideal-gas law resulting in $\sigma=0.00315$. All calculated values are very close to tabulated ISA values (Table A1 in Appendix) numerical difference being solely in using less significant digits (round-off errors). Utilizing expressions from Equation 37 and ISA SL properties given in Table 6 , the absolute temperature, pressure, and density now become $251 \mathrm{~K}\left(-22^{\circ} \mathrm{C}\right), 278 \mathrm{~Pa}$, and $0.00386 \mathrm{~kg} / \mathrm{m}^{3}$, respectively. Other physical air properties at $40 \mathrm{~km}$ could be calculated using expressions from Equation 38. This completes the example.

A classical pressure altimeter (aneroid barometer calibrated to indicate altitudes) is only capable of measuring local atmospheric pressure which always decrease with altitude. Therefore, pressure altitudes are always used in flight operations and in the specific case when 29.92 inch $\mathrm{Hg}$ or $1013.25 \mathrm{hPa}$ (mbar) are used for SL pressure than the standard pressure altitudes of flight levels are flown. The, so called, sensitive altimeter (not permanently fixed at 29.92 inch $\mathrm{Hg}$ ) can indeed adjust for changing SL pressure. However, the pressure altimeter cannot correct for variable (non-standard) temperatures and very cold temperatures would require additional height corrections when operating close to ground. Thus, from the standard tropospheric ISA model and local pressure measurement a pressure altitude (PA) can be calculated from:

$$
P A=H_{P A} \approx 4.4331 \times 10^{4} \cdot\left(1-\delta^{0.19}\right) \quad[\mathrm{m}]
$$

For example, if an aircraft is flying a constant 300 mbar $(300 \mathrm{hPa})$ pressure level in standard temperature and TLR condition, the pressure altitude will be about 9,153 m or 30,030 ft. All flights above 18,000 ft are designated FLs (Flight Levels) in USA and standard atmospheric pressure of 29.92 inch $\mathrm{Hg}$ (QNE) is used. Almost everywhere else FLs and transition altitudes/levels vary and can be as low as 5,000 ft. Below FL heights and as the local SL pressure (QNH) is decreasing and the sensitive altimeter's set point in, so called, Kollsman window is not readjusted to a new SL pressure a problem may arise. An aircraft will seem to be climbing (although it may not be doing so) as the local pressure at given altitude is decreasing. That will be subconsciously detected by pilot(s) trying to maintain constant pressure altitude and shallow descending flight will result. As pilot flies constant pressure altitude, the orthometric altitude is in fact decreasing, i.e., the proverbial "from high to low look out below" (FAA, 2015).

The main question is what is the sensitivity and uncertainty in pressure altitude measurements. A derivative of PA with respect to non-dimensional pressure (Equation 41) and PA uncertainty yield: 


$$
\frac{d H_{P A}}{d \delta} \approx\left(-0.84229 \times 10^{4}\right) \cdot \frac{1}{\delta^{0.81}} \Rightarrow \Delta H_{P A}=\left(\frac{d H_{P A}}{d \delta}\right) \Delta \delta
$$

Accordingly, a $0.5 \%$ error in pressure measurement (e.g., \pm 0.15 inch $\mathrm{Hg}$ ) at SL ISA $(\delta=1)$ due to instrument error or by not readjusting to current altimeter setting causes PA uncertainty of about $42 \mathrm{~m}(138 \mathrm{ft})$. Since $\left(d H_{P A} / d \delta\right)<0$, then for $\Delta \delta<0$, it follows that $\Delta H_{P A}>0$, which explains the above proverb. Consider also that pressure altimeter uncertainty is allowed to be $\pm 75 \mathrm{ft}$ which may add to non-standard pressures and temperatures errors. Flight operational details on pressure altimeter setting procedures can be found in (FAA, 2015).

Another altitude that can be derived from ISA considerations is TA (Temperature Altitude) defined for troposphere only as:

$T A=H_{T A}=-(1-\theta) \cdot \frac{T_{S L}}{\alpha_{0}} \approx 4.4330 .8 \cdot(1-\theta) \quad[\mathrm{m}]$

Unlike atmospheric pressure and density that are monotonically decreasing and have unique relationship to height, ISA temperature meanders throughout the atmosphere (see Figures 2 and 3). For example, a relative temperature $\theta=0.9$ corresponds to three different heights approximately: 4,500 $\mathrm{m}, 43,000 \mathrm{~m}$, and $55,000 \mathrm{~m}$ respectively. Additionally, the atmospheric temperature is least stable of all three principal thermodynamic air properties and it is no wonder that altitudes with reference to OAT (Outside Air Temperature) gage are not used.

A crucial performance altitude is, so-called, density altitude (DA) which for the standard troposphere results in:

$$
D A=H_{D A} \approx 4.4331 \times 10^{4} \cdot\left(1-\sigma^{0.235}\right) \quad[\mathrm{m}]
$$

However, the real atmosphere is neither still nor is the air dry. Although, the ISA concept assumes perfectly mixed atmosphere with localized overturning processes, the vertical motion and instability of real atmosphere can indeed become violent (Dutton, 2002; Saucier, 1989). Additionally, TLR and surface temperatures are normally not the same ones as utilized in ISA standard. For the standard atmosphere, the geopotential height is by definition equal to pressure 
height (Eshelby, 2000). For non-standard temperature, ISA deviation can be defined and geopotential and pressure altitudes differ by correction factor:

$$
d H=\left(\frac{T}{T_{S T D}}\right)_{P A} \cdot d H_{P A}=\left(\frac{\theta}{\theta_{S T D}}\right)_{P A} \cdot d H_{P A}
$$

This explains why for colder air in which temperature is below the standard value $T<T_{S T D}$, the geopotential (and thus orthometric) height is lower than corresponding pressure altitude, translating to "from warm to cold - also look out below". As the cold atmosphere compresses, the pressure levels will descend toward the Earth's surface.

\section{Conclusions}

Knowledge of standard atmospheric parameters is essential in aircraft design, performance testing, pressure altimeter calibration, and a plethora of other important aeronautical and aviation science applications. A concept of ISA was established to standardize such analysis globally. However, ISA values are typically given only in tabular form making them impractical for many applications. No specific algorithms for ISA computations are provided in the standard. A new general computational method for rapid calculation of standard atmospheric parameters for arbitrary altitudes up to $86 \mathrm{~km}$ has been developed and utilized here for the first time to the best of our knowledge. Base values of essential air parameters in ISA calculations have been computed and presented for each layer with at least seven significant digits accuracy. Essential thermodynamic theory and the basis for ideal-gas considerations of dry atmospheric air have been highlighted. The difference between the geopotential and orthometric altitudes and the definition of MSL has been clarified. It is believed that all these efforts were well warranted as most considerations of ISA in open literature lack deeper insight, consistency and completeness. Efforts made here also contribute to the comprehensiveness of theoretical considerations and facilitate putting standard atmospheric models on a stronger foundation. The ISA mass, weight, and scale heights have been estimated for the first time and are in good agreement with measurements and estimates of the real atmosphere. Pressure and density altitudes have been defined in terms of air thermodynamic parameters. In addition to many working equations a table of calculated nondimensional values up to $86 \mathrm{~km}$ has been provided. All computations have been performed with fourteen significant-digits precision although only seven significant digits were frequently shown. The concepts of pressure, temperature, and density altitudes were explained and its relationship to ISA highlighted. 
International Journal of Aviation, Aeronautics, and Aerospace, Vol. 2 [2015], Iss. 1, Art. 3

\section{Acknowledgment}

The author would like to express his gratitude to the Editorial Staff of the IJAAA for their assistance in conforming to manuscript formatting guidelines and in proof-reading the text. 


\section{Author Bios}

Dr. Nihad E. Daidzic is president of AAR Aerospace Consulting, L.L.C. He is also a full professor of Aviation, adjunct professor of Mechanical Engineering, and research graduate faculty at Minnesota State University, Mankato. His Ph.D. is in fluid mechanics and Sc.D. in mechanical engineering. He was formerly a staff scientist at the National Center for Microgravity Research and the National Center for Space Exploration and Research at NASA Glenn Research Center in Cleveland, OH. He has also held various faculty appointments at Vanderbilt University, University of Kansas, and Kent State University. His current research interest is in theoretical, experimental, and computational fluid dynamics, microand nano-fluidics, aircraft stability, control, and performance, mechanics of flight, piloting techniques, and aerospace propulsion. Dr. Daidzic is ATP and "Gold Seal" CFII/MEI/CFIG with flight experience in airplanes, helicopters, and gliders. 


\section{Appendix}

Table A1

Non-dimensional Temperature, Pressure, and Density for ISA up to $86 \mathrm{~km} \mathrm{MSL}$

\begin{tabular}{|c|c|c|c|c|c|c|}
\hline $\begin{array}{l}\text { Geopotential } \\
\text { Altitude [m] }\end{array}$ & $\begin{array}{l}\text { Orthometric } \\
\text { Altitude [m] }\end{array}$ & $\begin{array}{l}\text { Geopotential } \\
\text { Altitude [ft] }\end{array}$ & $\begin{array}{l}\text { Orthometric } \\
\text { Altitude [ft] }\end{array}$ & $\theta[-]$ & $\delta[-]$ & $\sigma[-]$ \\
\hline$-3,000$ & $-2,999$ & $-9,842$ & $-9,838$ & $1.067673 \mathrm{E}+00$ & $1.410809 \mathrm{E}+00$ & $1.321386 \mathrm{E}+00$ \\
\hline$-2,700$ & $-2,699$ & $-8,858$ & $-8,854$ & $1.060906 \mathrm{E}+00$ & $1.364439 \mathrm{E}+00$ & $1.286108 \mathrm{E}+00$ \\
\hline$-2,400$ & $-2,399$ & $-7,874$ & $-7,871$ & $1.054138 \mathrm{E}+00$ & $1.319311 \mathrm{E}+00$ & $1.251554 \mathrm{E}+00$ \\
\hline$-2,100$ & $-2,099$ & $-6,890$ & $-6,887$ & $1.047371 \mathrm{E}+00$ & $1.275400 \mathrm{E}+00$ & $1.217715 \mathrm{E}+00$ \\
\hline$-1,800$ & $-1,799$ & $-5,905$ & $-5,904$ & $1.040604 \mathrm{E}+00$ & $1.232679 \mathrm{E}+00$ & $1.184581 \mathrm{E}+00$ \\
\hline$-1,500$ & $-1,500$ & $-4,921$ & $-4,920$ & $1.033837 \mathrm{E}+00$ & $1.191125 \mathrm{E}+00$ & $1.152140 \mathrm{E}+00$ \\
\hline$-1,200$ & $-1,200$ & $-3,937$ & $-3,936$ & $1.027069 \mathrm{E}+00$ & $1.150712 \mathrm{E}+00$ & $1.120384 \mathrm{E}+00$ \\
\hline-600 & -600 & $-1,968$ & $-1,968$ & $1.013535 \mathrm{E}+00$ & $1.073215 \mathrm{E}+00$ & $1.058884 \mathrm{E}+00$ \\
\hline-900 & -900 & $-2,953$ & $-2,952$ & $1.020302 \mathrm{E}+00$ & $1.111417 \mathrm{E}+00$ & $1.089302 \mathrm{E}+00$ \\
\hline-600 & -600 & $-1,968$ & $-1,968$ & $1.013535 \mathrm{E}+00$ & $1.073215 \mathrm{E}+00$ & $1.058884 \mathrm{E}+00$ \\
\hline-300 & -300 & -984 & -984 & $1.006767 \mathrm{E}+00$ & $1.036084 \mathrm{E}+00$ & $1.029120 \mathrm{E}+00$ \\
\hline $\mathbf{0}$ & $\mathbf{0}$ & $\mathbf{0}$ & $\mathbf{0}$ & $1.000000 \mathrm{E}+00$ & $1.000000 \mathrm{E}+00$ & $1.000000 \mathrm{E}+00$ \\
\hline 300 & 300 & 984 & 984 & $9.932327 \mathrm{E}-01$ & 9.649403E-01 & 9.715149E-01 \\
\hline 600 & 600 & 1,968 & 1,969 & 9.864654E-01 & 9.308826E-01 & $9.436547 \mathrm{E}-01$ \\
\hline 900 & 900 & 2,953 & 2,953 & 9.796981E-01 & 8.978049E-01 & $9.164098 \mathrm{E}-01$ \\
\hline 1,200 & 1,200 & 3,937 & 3,938 & $9.729308 \mathrm{E}-01$ & $8.656855 \mathrm{E}-01$ & 8.897709E-01 \\
\hline 1,500 & 1,500 & 4,921 & 4,922 & $9.661635 \mathrm{E}-01$ & 8.345029E-01 & $8.637285 \mathrm{E}-01$ \\
\hline 1,800 & 1,801 & 5,905 & 5,907 & $9.593961 \mathrm{E}-01$ & 8.042361E-01 & 8.382732E-01 \\
\hline 2,100 & 2,101 & 6,890 & 6,892 & $9.526288 \mathrm{E}-01$ & 7.748644E-01 & $8.133959 \mathrm{E}-01$ \\
\hline 2,400 & 2,401 & 7,874 & 7,877 & $9.458615 \mathrm{E}-01$ & 7.463674E-01 & 7.890874E-01 \\
\hline 2,700 & 2,701 & 8,858 & 8,862 & 9.390942E-01 & $7.187250 \mathrm{E}-01$ & $7.653386 \mathrm{E}-01$ \\
\hline 3,000 & 3,001 & 9,842 & 9,847 & $9.323269 \mathrm{E}-01$ & 6.919175E-01 & $7.421405 \mathrm{E}-01$ \\
\hline 3,300 & 3,302 & 10,827 & 10,832 & $9.255596 \mathrm{E}-01$ & $6.659255 \mathrm{E}-01$ & 7.194842E-01 \\
\hline 3,600 & 3,602 & 11,811 & 11,818 & $9.187923 \mathrm{E}-01$ & $6.407298 \mathrm{E}-01$ & $6.973609 \mathrm{E}-01$ \\
\hline 3,900 & 3,902 & 12,795 & 12,803 & $9.120250 \mathrm{E}-01$ & $6.163116 \mathrm{E}-01$ & $6.757618 \mathrm{E}-01$ \\
\hline 4,200 & 4,203 & 13,779 & 13,788 & $9.052577 \mathrm{E}-01$ & $5.926525 \mathrm{E}-01$ & 6.546782E-01 \\
\hline 4,500 & 4,503 & 14,764 & 14,774 & 8.984904E-01 & 5.697343E-01 & 6.341017E-01 \\
\hline 4,800 & 4,804 & 15,748 & 15,760 & 8.917231E-01 & $5.475390 \mathrm{E}-01$ & $6.140236 \mathrm{E}-01$ \\
\hline
\end{tabular}




\begin{tabular}{|c|c|c|c|c|c|c|}
\hline 5,100 & 5,104 & 16,732 & 16,745 & $8.849558 \mathrm{E}-01$ & $5.260491 \mathrm{E}-01$ & $5.944355 \mathrm{E}-01$ \\
\hline 5,400 & 5,405 & 17,716 & 17,731 & 8.781884E-01 & $5.052473 \mathrm{E}-01$ & 5.753291E-01 \\
\hline 5,700 & 5,705 & 18,701 & 18,717 & $8.714211 \mathrm{E}-01$ & 4.851167E-01 & 5.566961E-01 \\
\hline 6,000 & 6,006 & 19,685 & 19,703 & 8.646538E-01 & 4.656405E-01 & 5.385283E-01 \\
\hline 6,300 & 6,306 & 20,669 & 20,689 & $8.578865 \mathrm{E}-01$ & 4.468024E-01 & $5.208176 \mathrm{E}-01$ \\
\hline 6,600 & 6,607 & 21,653 & 21,676 & 8.511192E-01 & 4.285862E-01 & $5.035560 \mathrm{E}-01$ \\
\hline 6,900 & 6,907 & 22,638 & 22,662 & 8.443519E-01 & 4.109761E-01 & 4.867355E-01 \\
\hline 7,200 & 7,208 & 23,622 & 23,648 & $8.375846 \mathrm{E}-01$ & $3.939565 \mathrm{E}-01$ & 4.703483E-01 \\
\hline 7,500 & 7,509 & 24,606 & 24,635 & 8.308173E-01 & $3.775122 \mathrm{E}-01$ & 4.543866E-01 \\
\hline 7,800 & 7,810 & 25,590 & 25,622 & $8.240500 \mathrm{E}-01$ & 3.616282E-01 & 4.388425E-01 \\
\hline 8,100 & 8,110 & 26,574 & 26,608 & 8.172827E-01 & 3.462897E-01 & $4.237086 \mathrm{E}-01$ \\
\hline 8,400 & 8,411 & 27,559 & 27,595 & $8.105154 \mathrm{E}-01$ & $3.314824 \mathrm{E}-01$ & 4.089773E-01 \\
\hline 8,700 & 8,712 & 28,543 & 28,582 & $8.037480 \mathrm{E}-01$ & $3.171919 \mathrm{E}-01$ & $3.946410 \mathrm{E}-01$ \\
\hline 9,000 & 9,013 & 29,527 & 29,569 & 7.969807E-01 & $3.034045 \mathrm{E}-01$ & 3.806924E-01 \\
\hline 9,300 & 9,314 & 30,511 & 30,556 & $7.902134 \mathrm{E}-01$ & $2.901064 \mathrm{E}-01$ & 3.671241E-01 \\
\hline 9,600 & 9,614 & 31,496 & 31,543 & 7.834461E-01 & $2.772842 \mathrm{E}-01$ & $3.539289 \mathrm{E}-01$ \\
\hline 9,900 & 9,915 & 32,480 & 32,530 & 7.766788E-01 & 2.649249E-01 & 3.410996E-01 \\
\hline 10,200 & 10,216 & 33,464 & 33,518 & 7.699115E-01 & $2.530154 \mathrm{E}-01$ & 3.286292E-01 \\
\hline 10,500 & 10,517 & 34,448 & 34,505 & 7.631442E-01 & $2.415432 \mathrm{E}-01$ & $3.165106 \mathrm{E}-01$ \\
\hline 10,800 & 10,818 & 35,433 & 35,493 & $7.563769 \mathrm{E}-01$ & $2.304959 \mathrm{E}-01$ & $3.047369 \mathrm{E}-01$ \\
\hline 11,000 & 11,019 & 36,089 & 36,151 & 7.518653E-01 & 2.233611E-01 & 2.970759E-01 \\
\hline 11,300 & 11,320 & 37,073 & 37,139 & $7.518653 \mathrm{E}-01$ & $2.130407 \mathrm{E}-01$ & $2.833495 \mathrm{E}-01$ \\
\hline 11,600 & 11,621 & 38,057 & 38,127 & $7.518653 \mathrm{E}-01$ & 2.031972E-01 & 2.702574E-01 \\
\hline 11,900 & 11,922 & 39,042 & 39,115 & $7.518653 \mathrm{E}-01$ & $1.938084 \mathrm{E}-01$ & $2.577701 \mathrm{E}-01$ \\
\hline 12,200 & 12,223 & 40,026 & 40,103 & $7.518653 \mathrm{E}-01$ & $1.848535 \mathrm{E}-01$ & $2.458599 \mathrm{E}-01$ \\
\hline 12,500 & 12,525 & 41,010 & 41,091 & $7.518653 \mathrm{E}-01$ & $1.763124 \mathrm{E}-01$ & $2.344999 \mathrm{E}-01$ \\
\hline 12,800 & 12,826 & 41,994 & 42,079 & $7.518653 \mathrm{E}-01$ & $1.681658 \mathrm{E}-01$ & $2.236648 \mathrm{E}-01$ \\
\hline 13,100 & 13,127 & 42,978 & 43,067 & 7.518653E-01 & $1.603957 \mathrm{E}-01$ & 2.133304E-01 \\
\hline 13,400 & 13,428 & 43,963 & 44,055 & 7.518653E-01 & $1.529846 \mathrm{E}-01$ & $2.034735 \mathrm{E}-01$ \\
\hline 13,700 & 13,730 & 44,947 & 45,044 & $7.518653 \mathrm{E}-01$ & $1.459160 \mathrm{E}-01$ & $1.940720 \mathrm{E}-01$ \\
\hline 14,000 & 14,031 & 45,931 & 46,032 & $7.518653 \mathrm{E}-01$ & $1.391739 \mathrm{E}-01$ & $1.851049 \mathrm{E}-01$ \\
\hline 14,300 & 14,332 & 46,915 & 47,021 & $7.518653 \mathrm{E}-01$ & $1.327434 \mathrm{E}-01$ & $1.765521 \mathrm{E}-01$ \\
\hline 14,600 & 14,634 & 47,900 & 48,010 & $7.518653 \mathrm{E}-01$ & $1.266100 \mathrm{E}-01$ & $1.683945 \mathrm{E}-01$ \\
\hline 14,900 & 14,935 & 48,884 & 48,999 & 7.518653E-01 & $1.207600 \mathrm{E}-01$ & $1.606138 \mathrm{E}-01$ \\
\hline 15,200 & 15,236 & 49,868 & 49,987 & $7.518653 \mathrm{E}-01$ & $1.151803 \mathrm{E}-01$ & $1.531927 \mathrm{E}-01$ \\
\hline 15,500 & 15,538 & 50,852 & 50,976 & 7.518653E-01 & $1.098584 \mathrm{E}-01$ & $1.461144 \mathrm{E}-01$ \\
\hline 15,800 & 15,839 & 51,837 & 51,966 & 7.518653E-01 & $1.047824 \mathrm{E}-01$ & $1.393632 \mathrm{E}-01$ \\
\hline
\end{tabular}




\begin{tabular}{|c|c|c|c|c|c|c|}
\hline 16,100 & 16,141 & 52,821 & 52,955 & $7.518653 \mathrm{E}-01$ & $9.994088 \mathrm{E}-02$ & $1.329239 \mathrm{E}-01$ \\
\hline 16,400 & 16,442 & 53,805 & 53,944 & 7.518653E-01 & $9.532312 \mathrm{E}-02$ & $1.267822 \mathrm{E}-01$ \\
\hline 16,700 & 16,744 & 54,789 & 54,933 & 7.518653E-01 & $9.091871 \mathrm{E}-02$ & 1.209242E-01 \\
\hline 17,000 & 17,045 & 55,774 & 55,923 & 7.518653E-01 & 8.671781E-02 & $1.153369 \mathrm{E}-01$ \\
\hline 17,300 & 17,347 & 56,758 & 56,912 & 7.518653E-01 & 8.271101E-02 & $1.100077 \mathrm{E}-01$ \\
\hline 17,600 & 17,649 & 57,742 & 57,902 & 7.518653E-01 & 7.888935E-02 & $1.049248 \mathrm{E}-01$ \\
\hline 17,900 & 17,950 & 58,726 & 58,892 & 7.518653E-01 & 7.524427E-02 & $1.000768 \mathrm{E}-01$ \\
\hline 18,200 & 18,252 & 59,711 & 59,882 & 7.518653E-01 & 7.176761E-02 & $9.545274 \mathrm{E}-02$ \\
\hline 18,500 & 18,554 & 60,695 & 60,872 & 7.518653E-01 & $6.845158 \mathrm{E}-02$ & $9.104234 \mathrm{E}-02$ \\
\hline 18,800 & 18,856 & 61,679 & 61,862 & 7.518653E-01 & $6.528878 \mathrm{E}-02$ & 8.683573E-02 \\
\hline 19,100 & 19,157 & 62,663 & 62,852 & 7.518653E-01 & $6.227211 \mathrm{E}-02$ & $8.282348 \mathrm{E}-02$ \\
\hline 19,400 & 19,459 & 63,648 & 63,842 & $7.518653 \mathrm{E}-01$ & 5.939482E-02 & 7.899662E-02 \\
\hline 19,700 & 19,761 & 64,632 & 64,832 & 7.518653E-01 & 5.665049E-02 & $7.534658 \mathrm{E}-02$ \\
\hline 20,000 & 20,063 & 65,616 & 65,823 & $7.518653 \mathrm{E}-01$ & 5.403295E-02 & $7.186520 \mathrm{E}-02$ \\
\hline 20,300 & 20,365 & 66,600 & 66,813 & $7.529065 \mathrm{E}-01$ & $5.153804 \mathrm{E}-02$ & $6.845212 \mathrm{E}-02$ \\
\hline 20,600 & 20,667 & 67,584 & 67,804 & 7.539476E-01 & 4.916155E-02 & $6.520552 \mathrm{E}-02$ \\
\hline 20,900 & 20,969 & 68,569 & 68,794 & 7.549887E-01 & 4.689769E-02 & $6.211707 \mathrm{E}-02$ \\
\hline 21,200 & 21,271 & 69,553 & 69,785 & $7.560298 \mathrm{E}-01$ & 4.474099E-02 & $5.917887 \mathrm{E}-02$ \\
\hline 21,500 & 21,573 & 70,537 & 70,776 & $7.570710 \mathrm{E}-01$ & 4.268623E-02 & $5.638340 \mathrm{E}-02$ \\
\hline 21,800 & 21,875 & 71,521 & 71,767 & $7.581121 \mathrm{E}-01$ & $4.072848 \mathrm{E}-02$ & $5.372356 \mathrm{E}-02$ \\
\hline 22,100 & 22,177 & 72,506 & 72,758 & 7.591532E-01 & 3.886301E-02 & $5.119258 \mathrm{E}-02$ \\
\hline 22,400 & 22,479 & 73,490 & 73,749 & 7.601943E-01 & $3.708538 \mathrm{E}-02$ & 4.878407E-02 \\
\hline 22,700 & 22,781 & 74,474 & 74,740 & 7.612355E-01 & 3.539132E-02 & 4.649194E-02 \\
\hline 23,000 & 23,083 & 75,458 & 75,732 & 7.622766E-01 & 3.377680E-02 & 4.431043E-02 \\
\hline 23,300 & 23,386 & 76,443 & 76,723 & 7.633177E-01 & $3.223799 \mathrm{E}-02$ & 4.223404E-02 \\
\hline 23,600 & 23,688 & 77,427 & 77,715 & $7.643588 \mathrm{E}-01$ & 3.077124E-02 & 4.025759E-02 \\
\hline 23,900 & 23,990 & 78,411 & 78,706 & $7.654000 \mathrm{E}-01$ & $2.937309 \mathrm{E}-02$ & $3.837613 \mathrm{E}-02$ \\
\hline 24,200 & 24,292 & 79,395 & 79,698 & 7.664411E-01 & 2.804024E-02 & 3.658499E-02 \\
\hline 24,500 & 24,595 & 80,380 & 80,690 & 7.674822E-01 & 2.676955E-02 & $3.487971 \mathrm{E}-02$ \\
\hline 25,000 & 25,098 & 82,020 & 82,343 & 7.692174E-01 & 2.478187E-02 & $3.221699 \mathrm{E}-02$ \\
\hline 26,000 & 26,107 & 85,301 & 85,650 & $7.726878 \mathrm{E}-01$ & $2.124938 \mathrm{E}-02$ & $2.750061 \mathrm{E}-02$ \\
\hline 27,000 & 27,115 & 88,582 & 88,959 & 7.761583E-01 & $1.823299 \mathrm{E}-02$ & $2.349133 \mathrm{E}-02$ \\
\hline 28,000 & 28,124 & 91,862 & 92,268 & 7.796287E-01 & $1.565546 \mathrm{E}-02$ & $2.008067 \mathrm{E}-02$ \\
\hline 29,000 & 29,133 & 95,143 & 95,578 & 7.830991E-01 & 1.345142E-02 & $1.717716 \mathrm{E}-02$ \\
\hline 30,000 & 30,142 & 98,424 & 98,890 & $7.865695 \mathrm{E}-01$ & 1.156542E-02 & $1.470363 \mathrm{E}-02$ \\
\hline 31,000 & 31,152 & 101,705 & 102,202 & 7.900399E-01 & $9.950476 \mathrm{E}-03$ & $1.259490 \mathrm{E}-02$ \\
\hline 32,000 & 32,162 & 104,986 & 105,516 & 7.935103E-01 & 8.566678E-03 & 1.079593E-02 \\
\hline
\end{tabular}




\begin{tabular}{|c|c|c|c|c|c|c|}
\hline 33,000 & 33,172 & 108,266 & 108,830 & $8.032275 \mathrm{E}-01$ & 7.384439E-03 & $9.193459 \mathrm{E}-03$ \\
\hline 34,000 & 34,182 & 111,547 & 112,146 & $8.129446 \mathrm{E}-01$ & $6.376731 \mathrm{E}-03$ & 7.843991E-03 \\
\hline 35,000 & 35,193 & 114,828 & 115,462 & $8.226618 \mathrm{E}-01$ & $5.516146 \mathrm{E}-03$ & $6.705242 \mathrm{E}-03$ \\
\hline 36,000 & 36,205 & 118,109 & 118,780 & $8.323790 \mathrm{E}-01$ & 4.779834E-03 & $5.742378 \mathrm{E}-03$ \\
\hline 37,000 & 37,216 & 121,390 & 122,099 & 8.420961E-01 & 4.148701E-03 & 4.926636E-03 \\
\hline 38,000 & 38,228 & 124,670 & 125,418 & 8.518133E-01 & $3.606758 \mathrm{E}-03$ & $4.234212 \mathrm{E}-03$ \\
\hline 39,000 & 39,240 & 127,951 & 128,739 & 8.615305E-01 & 3.140592E-03 & 3.645364E-03 \\
\hline 40,000 & 40,253 & 131,232 & 132,061 & $8.712476 \mathrm{E}-01$ & $2.738925 \mathrm{E}-03$ & 3.143681E-03 \\
\hline 41,000 & 41,266 & 134,513 & 135,384 & 8.809648E-01 & $2.392257 \mathrm{E}-03$ & $2.715497 \mathrm{E}-03$ \\
\hline 42,000 & 42,279 & 137,794 & 138,708 & 8.906819E-01 & $2.092572 \mathrm{E}-03$ & $2.349405 \mathrm{E}-03$ \\
\hline 43,000 & 43,292 & 141,074 & 142,033 & $9.003991 \mathrm{E}-01$ & $1.833090 \mathrm{E}-03$ & $2.035864 \mathrm{E}-03$ \\
\hline 44,000 & 44,306 & 144,355 & 145,359 & $9.101163 \mathrm{E}-01$ & $1.608067 \mathrm{E}-03$ & $1.766881 \mathrm{E}-03$ \\
\hline 45,000 & 45,320 & 147,636 & 148,686 & $9.198334 \mathrm{E}-01$ & $1.412631 \mathrm{E}-03$ & $1.535746 \mathrm{E}-03$ \\
\hline 46,000 & 46,335 & 150,917 & 152,014 & $9.295506 \mathrm{E}-01$ & $1.242638 \mathrm{E}-03$ & $1.336816 \mathrm{E}-03$ \\
\hline 47,000 & 47,349 & 154,198 & 155,344 & 9.392677E-01 & $1.094560 \mathrm{E}-03$ & 1.165333E-03 \\
\hline 48,000 & 48,364 & 157,478 & 158,674 & 9.392677E-01 & 9.647619E-04 & $1.027143 \mathrm{E}-03$ \\
\hline 49,000 & 49,380 & & 162,005 & $9.392677 \mathrm{E}-01$ & 8.503559E-04 & $9.053391 \mathrm{E}-04$ \\
\hline 50,000 & 50,396 & 164,040 & 165,338 & 9.392677E-01 & 7.495166E-04 & 7.979797E-04 \\
\hline 51,000 & 51,412 & 167,321 & 168,671 & $9.392677 \mathrm{E}-01$ & 6.606353E-04 & 7.033514E-04 \\
\hline 52,000 & 52,428 & 170,602 & 172,006 & $9.295506 \mathrm{E}-01$ & 5.819113E-04 & $6.260136 \mathrm{E}-04$ \\
\hline 53,000 & 53,445 & 173,882 & 175,341 & 9.198334E-01 & 5.118854E-04 & $5.564979 \mathrm{E}-04$ \\
\hline 54,000 & 54,462 & 177,163 & 178,678 & $9.101163 \mathrm{E}-01$ & 4.496734E-04 & 4.940835E-04 \\
\hline 55,000 & 55,479 & 180,444 & 182,015 & $9.003991 \mathrm{E}-01$ & 3.944734E-04 & $4.381095 \mathrm{E}-04$ \\
\hline 56,000 & 56,497 & 183,725 & 185,354 & 8.906819E-01 & $3.455580 \mathrm{E}-04$ & 3.879702E-04 \\
\hline 57,000 & 57,515 & 187,006 & 188,694 & 8.809648E-01 & $3.022689 \mathrm{E}-04$ & $3.431112 \mathrm{E}-04$ \\
\hline 58,000 & 58,533 & 190,286 & 192,035 & $8.712476 \mathrm{E}-01$ & $2.640106 \mathrm{E}-04$ & $3.030259 \mathrm{E}-04$ \\
\hline 59,000 & 59,551 & 193,567 & 195,377 & $8.615305 \mathrm{E}-01$ & $2.302449 \mathrm{E}-04$ & $2.672510 \mathrm{E}-04$ \\
\hline 60,000 & 60,570 & 196,848 & 198,719 & $8.518133 \mathrm{E}-01$ & $2.004862 \mathrm{E}-04$ & $2.353640 \mathrm{E}-04$ \\
\hline 61,000 & 61,590 & 200,129 & 202,063 & 8.420961E-01 & $1.742968 \mathrm{E}-04$ & $2.069796 \mathrm{E}-04$ \\
\hline 62,000 & 62,609 & 203,410 & 205,409 & $8.323790 \mathrm{E}-01$ & $1.512825 \mathrm{E}-04$ & $1.817471 \mathrm{E}-04$ \\
\hline 63,000 & 63,629 & 206,690 & 208,755 & 8.226618E-01 & $1.310888 \mathrm{E}-04$ & $1.593471 \mathrm{E}-04$ \\
\hline 64,000 & 64,649 & 209,971 & 212,102 & $8.129446 \mathrm{E}-01$ & $1.133975 \mathrm{E}-04$ & $1.394898 \mathrm{E}-04$ \\
\hline 65,000 & 65,670 & 213,252 & 215,450 & $8.032275 \mathrm{E}-01$ & $9.792282 \mathrm{E}-05$ & $1.219117 \mathrm{E}-04$ \\
\hline 66,000 & 66,691 & 216,533 & 218,799 & 7.935103E-01 & $8.440904 \mathrm{E}-05$ & $1.063742 \mathrm{E}-04$ \\
\hline 67,000 & 67,712 & 219,814 & 222,150 & 7.837932E-01 & $7.262720 \mathrm{E}-05$ & $9.266118 \mathrm{E}-05$ \\
\hline 68,000 & 68,734 & 223,094 & 225,501 & $7.740760 \mathrm{E}-01$ & $6.237278 \mathrm{E}-05$ & $8.057708 \mathrm{E}-05$ \\
\hline 69,000 & 69,755 & 226,375 & 228,854 & 7.643588E-01 & $5.346331 \mathrm{E}-05$ & $6.994531 \mathrm{E}-05$ \\
\hline
\end{tabular}




\begin{tabular}{|r|r|r|r|r|r|r|}
\hline 70,000 & 70,778 & 229,656 & 232,207 & $7.546417 \mathrm{E}-01$ & $4.573621 \mathrm{E}-05$ & $6.060653 \mathrm{E}-05$ \\
\hline $\mathbf{7 1 , 0 0 0}$ & $\mathbf{7 1 , 8 0 0}$ & $\mathbf{2 3 2 , 9 3 7}$ & $\mathbf{2 3 5 , 5 6 2}$ & $\mathbf{7 . 4 4 9 2 4 5 E - 0 1}$ & $\mathbf{3 . 9 0 4 6 8 3 E - 0 5}$ & $\mathbf{5 . 2 4 1 7 1 7 E - 0 5}$ \\
\hline 72,000 & 72,823 & 236,218 & 238,918 & $7.379837 \mathrm{E}-01$ & $3.327672 \mathrm{E}-05$ & $4.509140 \mathrm{E}-05$ \\
\hline 73,000 & 73,846 & 239,498 & 242,274 & $7.310429 \mathrm{E}-01$ & $2.831646 \mathrm{E}-05$ & $3.873433 \mathrm{E}-05$ \\
\hline 74,000 & 74,870 & 242,779 & 245,632 & $7.241020 \mathrm{E}-01$ & $2.405850 \mathrm{E}-05$ & $3.322529 \mathrm{E}-05$ \\
\hline 75,000 & 75,893 & 246,060 & 248,991 & $7.171612 \mathrm{E}-01$ & $2.040876 \mathrm{E}-05$ & $2.845770 \mathrm{E}-05$ \\
\hline 76,000 & 76,918 & 249,341 & 252,351 & $7.102204 \mathrm{E}-01$ & $1.728501 \mathrm{E}-05$ & $2.433754 \mathrm{E}-05$ \\
\hline 77,000 & 77,942 & 252,622 & 255,712 & $7.032795 \mathrm{E}-01$ & $1.461552 \mathrm{E}-05$ & $2.078195 \mathrm{E}-05$ \\
\hline 78,000 & 78,967 & 255,902 & 259,074 & $6.963387 \mathrm{E}-01$ & $1.233776 \mathrm{E}-05$ & $1.771804 \mathrm{E}-05$ \\
\hline 79,000 & 79,992 & 259,183 & 262,437 & $6.893979 \mathrm{E}-01$ & $1.039731 \mathrm{E}-05$ & $1.508173 \mathrm{E}-05$ \\
\hline 80,000 & 81,017 & 262,464 & 265,802 & $6.824571 \mathrm{E}-01$ & $8.746899 \mathrm{E}-06$ & $1.281678 \mathrm{E}-05$ \\
\hline 81,000 & 82,043 & 265,745 & 269,167 & $6.755162 \mathrm{E}-01$ & $7.345470 \mathrm{E}-06$ & $1.087386 \mathrm{E}-05$ \\
\hline 82,000 & 83,069 & 269,026 & 272,533 & $6.685754 \mathrm{E}-01$ & $6.157464 \mathrm{E}-06$ & $9.209828 \mathrm{E}-06$ \\
\hline 83,000 & 84,096 & 272,306 & 275,901 & $6.616346 \mathrm{E}-01$ & $5.152104 \mathrm{E}-06$ & $7.786933 \mathrm{E}-06$ \\
\hline 84,000 & 85,122 & 275,587 & 279,269 & $6.546937 \mathrm{E}-01$ & $4.302798 \mathrm{E}-06$ & $6.572230 \mathrm{E}-06$ \\
\hline $\mathbf{8 4 , 8 5 2}$ & $\mathbf{8 5 , 9 9 7}$ & $\mathbf{2 7 8 , 3 8 2}$ & $\mathbf{2 8 2 , 1 4 0}$ & $\mathbf{6 . 4 8 7 8 0 1 E - 0 1}$ & $\mathbf{3 . 6 8 5 0 1 0 E}-\mathbf{0 6}$ & $\mathbf{5 . 6 7 9 9 0 5 E - 0 6}$ \\
\hline
\end{tabular}

Note. Bold numbers define SL conditions or borders between ISA layers. 


\section{References}

Anderson, J. D. Jr. (2012). Introduction to flight (7th ed.). New York, NY: McGraw-Hill.

Asselin, M. (1997). An introduction to aircraft performance. Reston, VA: American Institute for Aeronautics and Astronautics.

Bertin, J. J., \& Cummings, R. M. (2009). Aerodynamics for engineers (5th ed.). Upper Saddle River, NJ: Pearson Prentice Hall.

Chapra, S. C., \& Canale, R. P. (2006). Numerical methods for engineers (5th ed.). New York, NY: McGraw-Hill.

Daidzic, N. E., \& Simones, M. (2010). Aircraft decompression with installed cockpit security door, Journal of Aircraft, 47(2), 490-504. doi: $10.2514 / 1.41953$

Davies, M. (Ed.) (2003). The standard handbook for aeronautical and astronomical engineers. New York, NY: McGraw-Hill.

Dutton, J. A. (2002). The ceaseless wind: An introduction to the theory of atmospheric motion. Mineola, NY: Dover.

Eshelby, M. E. (2000). Aircraft performance: Theory and practice. Boston, MA: Elsevier.

Federal Aviation Administration. (2015). FAR AIM: Federal aviation regulations and aeronautical information manual. Rules and procedures for aviators (ASA-15-FR-AM-BK). Newcastle, WA: Aviation Supplies \& Academics.

Filippone, A. (2006). Flight performance of fixed and rotary wing aircraft. Reston, VA: American Institute for Aeronautics and Astronautics.

Filippone, A. (2012). Advanced aircraft flight performance. Cambridge, UK: University Press.

Granger, R. A. (1995). Fluid mechanics. New York, NY: Dover.

Hale, F. J. (1984). Introduction to aircraft performance, selection, and design. New York, NY: John Wiley \& Sons. 
Holman, J. P. (1980). Thermodynamics (3rd ed.). Singapore, Singapore: McGrawHill.

Hubin, W. N. (1992). The science of flight: Pilot-oriented aerodynamics. Ames, IA: State University Press.

Hurt, H. H., Jr. (1965). Aerodynamics for naval aviators. Renton, WA: Aviation Supplies and Academics.

International Civil Aviation Organization. (1993). Manual of the ICAO Standard Atmosphere (extended to 80 kilometers (262 500 feet)) (Doc 7488-CD, 3rd ed.). Montreal, Canada: Author.

International Organization for Standardization. (1975). Standard Atmosphere (ISO 2533:1975/Add. 2: 1997(en)). Geneva, Switzerland: Author.

Iribarne, J. V., \& Cho, H.-R. (1980). Atmospheric physics. Dordrecht, Holland: D. Reidel.

Lay, J. E. (1963). Thermodynamics. Columbus, OH: Charles E. Merrill.

Liepmann, H. W., \& Roshko, A. (2001). Elements of gasdynamics. Mineola, NY: Dover.

Mair, W. A., \& Birdsall, D. L. (1992). Aircraft performance. Cambridge, UK: University Press.

McCormick, B. W. (1995). Aerodynamics, aeronautics, and flight mechanics (2nd ed.). New York, NY: John Wiley \& Sons.

Nicolai, L. M., \& Carichner, G. E. (2010). Fundamentals of aircraft and airship design: Volume I - aircraft design. Reston, VA: American Institute for Aeronautics and Astronautics (AIAA).

National Oceanic and Atmospheric Administration. (1976). U.S. Standard Atmosphere, 1976 (NOAA-S/T 76-1562). Washington, DC: U.S. Government Printing Office.

Phillips, W. F. (2004). Mechanics of flight, Hoboken, NJ: John Wiley \& Sons. 
Press, W. H, Teulkolsky, S. A., Vetterling, W. T., \& Flannery, B. P. (1992). Numerical recipes in FORTRAN: The art of scientific computing (2nd ed.). Cambridge, UK: University Press.

Saad, M. (1966). Thermodynamics for engineers. Englewood Cliffs, NJ: Prentice Hall.

Saarlas, M. (2007). Aircraft performance. Hoboken, NJ: John Wiley \& Sons.

Saucier, W. J. (1989). Principles of meteorological analysis. New York, NY: Dover.

Torenbeek, E. (2013). Advanced aircraft design: Conceptual design, technology and optimization of subsonic civil airplanes. Chichester, West Sussex, UK: John Wiley \& Sons.

Trenberth, K. E., \& Smith, L. (2005). The mass of the atmosphere: A constraint on global analysis. Journal of Climate, 18, 864-875. doi: 10.1175/JCLI3299.1

Vinh, N. X. (1993). Flight mechanics of high-performance aircraft. Cambridge, UK: University Press. 